\title{
LEAF FUNCTIONAL TRAITS AS PREDICTORS OF DROUGHT TOLERANCE IN URBAN TREES
}

\author{
A Thesis \\ presented to \\ the Faculty of California Polytechnic State University, \\ San Luis Obispo \\ In Partial Fulfillment \\ of the Requirements for the Degree \\ Master of Science in Agriculture, \\ Specialization in Environmental Horticultural Science
}

by

Sophia Huang

June 2019 
(C) 2019

Sophia Huang

ALL RIGHTS RESERVED 
TITLE: Leaf Functional Traits as Predictors of Drought Tolerance in Urban Trees

AUTHOR: Sophia Huang

DATE SUBMITTED: June 2019

COMMITTEE CHAIR: Benjamin K. Hoover, Ph.D.

Assistant Professor of Horticulture and Crop Science

COMMITTEE MEMBER: Charles A. Knight, Ph.D.

Professor of Biology

COMMITTEE MEMBER: Matthew Ritter, Ph.D.

Professor of Biology 


\section{ABSTRACT \\ Leaf Functional Traits as Predictors of Drought Tolerance in Urban Trees Sophia Huang}

The services that urban trees provide to human society and the natural environment are widely recognized, but urban trees are in jeopardy due to climate change and urban stressors. With drought as a major threat in many areas, it is important for the future of urban forestry to select species composition based upon performance under water stress. Certain leaf functional traits can help horticulturalists more accurately predict water usage of urban trees. Comprehension through rigorous experimentation is lacking, partly due to the thousands of mostly exotic species. Previous studies suggest that species whose leaves have a denser arrangement of smaller stomata and a higher leaf mass per area (LMA) are better adapted to low water availability. We sampled 70 urban tree species California and analyzed their stomatal length, stomatal density, and LMA. We compared the traits with water use data from the Water Use Classification of Landscape Species to assess possible correlations. All pairwise trait comparisons show significant correlation $(P<0.05)$, and LMA is significantly higher in low water use species compared to medium water use species $(P=0.0045)$. After using independent contrasts to incorporate phylogenetic relationships, significance was lost, implying that basal divergences are responsible for observed trends. Other potential explanations for differences in species water usage are foliar longevity (deciduous vs. evergreen) and stomatal distribution (amphistomatous vs. hypostomatous). Low water use species are more likely to be evergreen and amphistomatous compared to medium water use species. Consideration of all these traits in combination with good management practices can help ensure future success of urban forests.

Keywords: urban forests, leaf functional traits, stomata, LMA, water usage, drought 


\section{ACKNOWLEDGMENTS}

I thank the Wertmann and Boyle-McOmie Scholarships for the generous support that made graduate studies and research possible. The community of excellent teachers and curiosity-driven plant scientists at Cal Poly University helped support and motivate my learning experience. I would like to thank Dr. Benjamin Hoover for his valuable input and consistent mentorship throughout the entire graduate process. This project initiated from stimulating conversation and ideas with Dr. Charles Knight, who to this day continues to develop my inquisitive, botanical mind. My graduate experience would not have been as rich and fulfilling without Dr. Matt Ritter, who provided insightful feedback and numerous botanical opportunities. And finally, I would like to thank my parents who have always supported me in my pursuit of a productive, rewarding life by providing an education and understanding my passion for plants. 


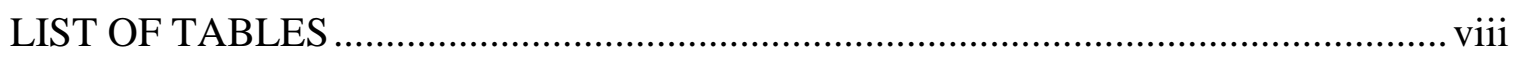

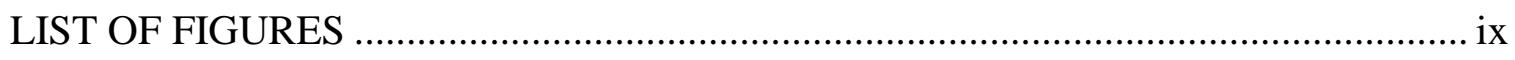

\section{CHAPTER}

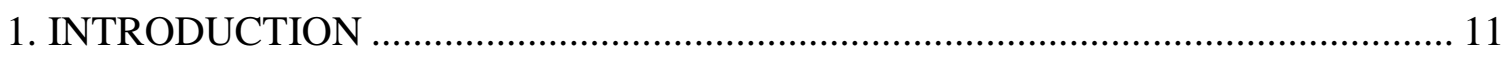

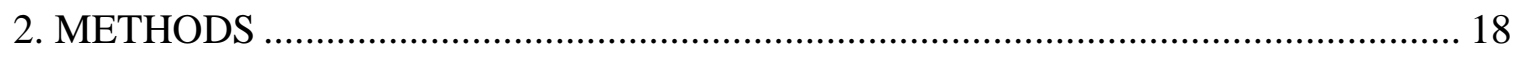

2.1 Species Selection and Leaf Collection............................................................. 18

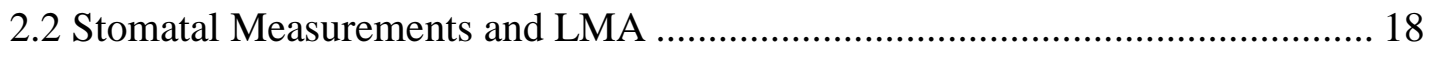

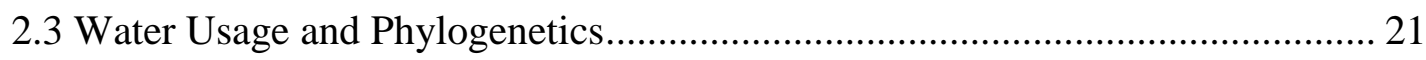

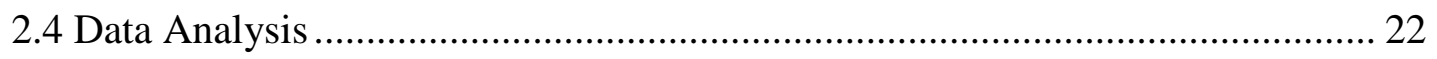

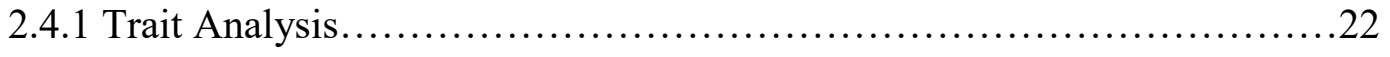

2.4.2 Predicitve Model..................................................22

2.4.3 Phyogenetic Analysis....................................................23

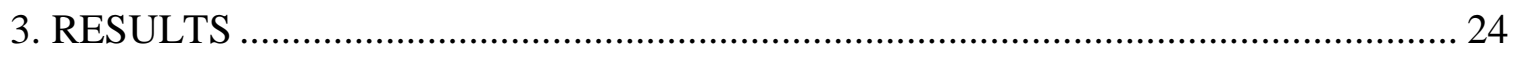

3.1 Leaf Functional Traits and Water Usage across Species ..................................... 24

3.2 Correlations between Leaf Functional Traits................................................... 27

3.3 Comparison by Water Usage ....................................................................... 29

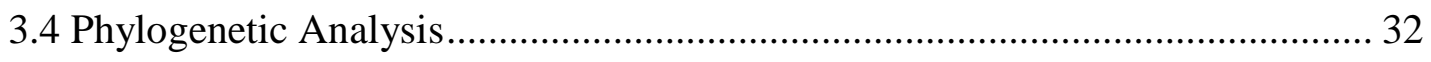

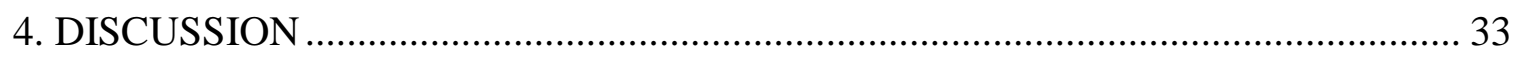

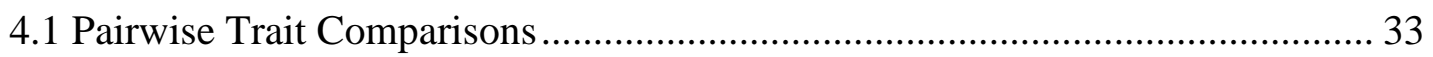


4.2 Phylogenetics

4.3 Stomatal Distribution on Both Leaf Surfaces

4.4 Other Explanations for Differences in Water Usage

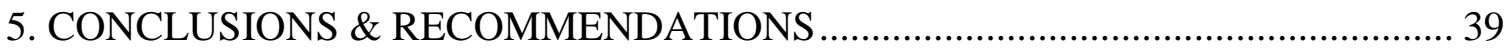

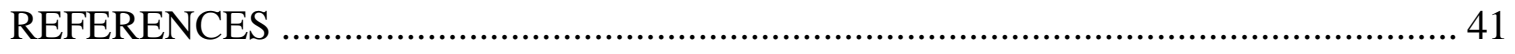

\section{APPENDICES}

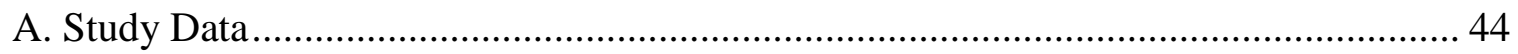

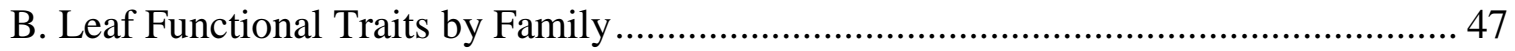

C. Urban Tree Water Usage from Various Sources..................................................... 49 


\section{LIST OF TABLES}

Table

Page

1. Pairwise Trait Comparisons Using Correlation and Independent Contrast. ................. 32

2. Compiled Data for all 70 Tree Species Sampled................................................... 44

3. Water Usage of Eight Representative Urban Tree Species Common in

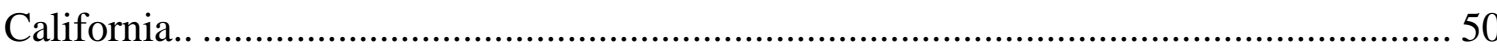




\section{LIST OF FIGURES}

Figures

Page

1. Process of Making Epidermal Peels.. ................................................................... 19

2. Images of Stomata as Viewed in Image J 1.x with Calibration Scale. ....................... 20

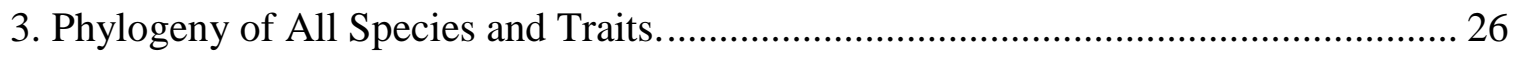

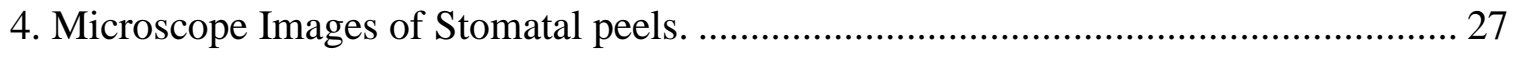

5. Relationship Between Mean Abaxial Stomatal Length $(\mu \mathrm{m})$ and Mean Abaxial

Stomatal Density $\left(\# / \mathrm{mm}^{2}\right)$ across 70 Tree Species................................................... 28

6. Relationship Between Mean Abaxial Stomata Length and LMA across 70 Tree

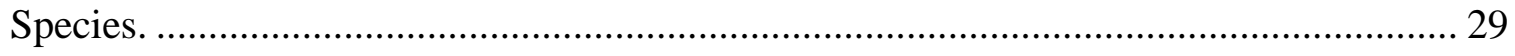

7. Relationship Between Mean Abaxial Stomatal Density and LMA across 70 Tree

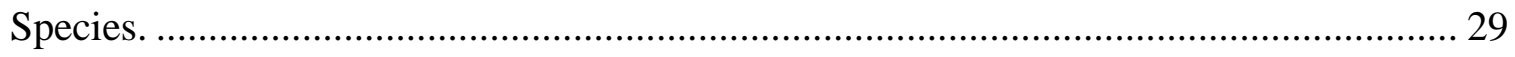

8. Comparisons of Various Leaf Morphological Traits of Trees with Low $(n=30)$ and

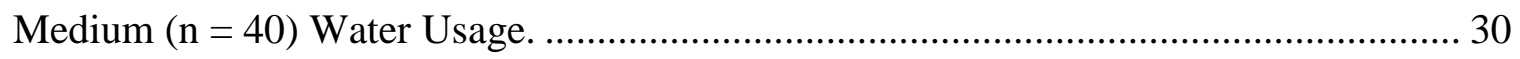

9. Comparison of Water Usage for Amphistomatous and Hypostomatous Tree

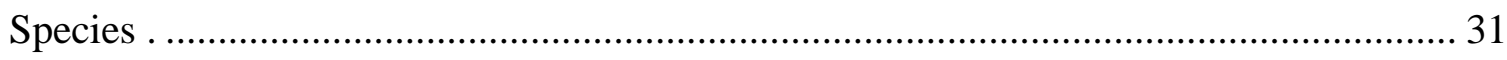

10. Scatterplot of Mean Stomatal Density $\left(\# / \mathrm{mm}^{2}\right)$ and Mean LMA $\left(\mathrm{g} / \mathrm{m}^{2}\right)$ for Orders $(\mathrm{n}=7)$ and Super Orders $(\mathrm{n}=1)$ with More Than Three Species.

11. Comparison of Mean LMA $\left(\mathrm{g} / \mathrm{m}^{2}\right)$ between Amphistomatous and Hypostomatous

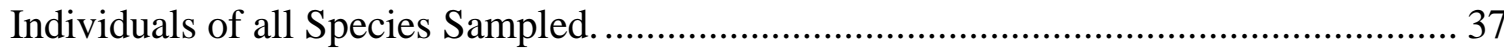

12. Relationship between Foliar Longevity (evergreen or winter deciduous) and Water Usage (low or medium). 38 


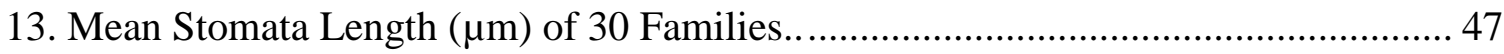

14. Mean Stomatal Density $\left(\# / \mathrm{mm}^{2}\right)$ of 30 Families. ..................................................... 48

15. Average Leaf Mass per Area (LMA) $\mathrm{g} / \mathrm{m}^{2}$ ) of 30 Families...................................... 48 


\section{CHAPTER 1}

\section{Introduction}

Urban forests are subject to various urban environmental stressors, such as soil compaction, heat island effects, and water stress. Therefore, selecting trees that can tolerate these stress conditions is critical to maintain the health of future urban forests (McPherson et al., 2017). In California and other parts of the American West, urban forests are under increasing water stress due to consecutive years of drought. Most horticultural plant water usage data is not supported by rigorous experimentation and no theoretical method of predicting a plant species' water use has been well established (Costello and Jones, 2014: McPherson et al., 2018). Therefore, development of theoretical models to assess tree species' suitability to urban environments can aid in future selection, maintenance, and success of urban forests.

In many places, rising frequency of drought, combined with other aspects of climate change and existing stressors imposed by the urban environment, mean increased mortality of the urban forest (McPherson et al., 2017). Since adequate water is necessary for maintenance of hydraulic conductance and essential biochemical processes, drought is commonly determined to be a primary urban stress as well as cause of premature mortality in landscape plants (Bradshaw et al., 1995; Cameron, 2003). For regions where drought is a major threat, it is important for the future of urban forestry to select species composition based upon performance under water stress. 
Current research on future performance of urban tree species focuses on recommendations by horticulturalists based upon known characteristics and stress tolerance abilities (McPherson et al., 2018). Physiological traits, measured by phenomena such as chlorophyll fluorescence (Ow etal., 2011) and photosystem activity (Swoczyna et al., 2015), are also useful predictors of plants' tolerance to water stress. In addition to physiology are leaf functional traits, such as the presence of stomata and their characteristics, which influence the balance of evapotranspiration and photosynthesis in plants.

Two important stomatal characteristics are size and density, which are species specific (Casson and Gray, 2007). The stomatal size, measured by guard cell length, and stomatal density and are generally inversely correlated within species (Beaulieu et al., 2008). As stomatal length increases, each individual stoma occupies more leaf epidermal area, so the entire leaf epidermis can hold a less dense arrangement of stomata. Research across 101 angiosperm species strongly supports the relationship of decreasing stomatal density with increasing stomatal length and suggests that these traits may influence a species' ecological fitness (Beaulieu et al., 2008).

A relatively dense arrangement of smaller stomata may allow for more rapid and sensitive response to changes in water availability (Hetherington and Woodward, 2003). In existing studies of agricultural olive trees (Olea europea L.) and wild grassland species, a higher stomatal index has sometimes resulted in greater plant success under conditions of water deprivation (Hardy et al., 1995; Bosabalidis and Kofidis, 2002; Xu 
and Zhou, 2008). When cultivated under both well-irrigated and water-stressed conditions, a given cultivar of olive tree developed increased stomatal density under the water-stressed condition (Bosabalidis and Kofidis, 2002). Another study on the grass Leymus chinensis (Trin.) Trzvelev showed a positive relationship between stomatal density and increasing water stress (Xu and Zhou, 2008). As water stress increased, stomatal length decreased, stomatal length increased, and water-use efficiency (WUE) increased (Xu and Zhou, 2008).

In wild grassland ecosystems, some species of grass utilize $\mathrm{C}_{4}$ photosynthesis, which has higher water-use efficiency (WUE) than $\mathrm{C}_{3}$ photosynthesis (Hardy et al., 1995). Thus, $\mathrm{C}_{4}$ photosynthesis is indicative of higher water stress tolerance, and studies have shown that $\mathrm{C}_{4}$ grass species have higher stomatal densities than $\mathrm{C}_{3}$ grass species found in similar habitat (Hardy et al., 1995). However, few trees utilize $\mathrm{C}_{4}$ photosynthesis, other than a few species of Euphorbia (Sage, 2014) which are not common Californian urban tree species, so $\mathrm{C}_{4}$ photosynthesis is not considered any further.

The distribution of stomata on both leaf surfaces also influences a plant's rate of photosynthesis and water loss. Hypostomaty, the possession of stomata on only the abaxial (lower) surface of leaves is considered an ancestral trait in plants (Mott et al., 1982). Amphistomaty, the development on stomata on both abaxial and adaxial (upper) leaf surfaces is a derived trait that may be related to environmental conditions (Parkhurst, 1978; Mott et al., 1982). Amphistomatous species are more likely than hypostomatous species to exist in xeric environments with abundant radiation where carbon diffusion is 
the sole limiting factor of photosynthesis (Parkhurst, 1978; Mott et al., 1982).

Amphistomaty is also positively correlated with leaf thickness, possibly because thicker mesophyll tissue requires stomata on both leaf surfaces for adequate gas diffusion (Mott et al., 1982). Studies in Mediterranean plants (Rhizopoulou and Psaras, 2003; Yiotis et al., 2006) and American Southwest plants show correlation between amphistomaty and leaf thickness, measured by leaf mass per area (LMA).

Research on the relationship between amphistomaty and drought tolerance is lacking, but there are speculative explanations for the observed amphistomaty in xeric plant species. Since xeric environments are associated with having greater exposure to light, it may be advantageous for species in these environments to develop amphistomaty if carbon diffusion is the only limiting factor to photosynthesis. Although a plant can increase size or density of stomata on the abaxial leaf surface, increasing stomatal density may eventually decrease the efficiency of carbon diffusion into the leaf, making adaxial stomata more advantageous. It may appear that if amphistomatous leaves have higher leaf conductance, then they will require more water to account for increased evapotranspiration. However, it is unnecessary for a plant with high leaf conductance to maintain maximum conductance and the plant can do so only when environmental conditions favor and allow for higher photosynthetic activity and higher water loss (Parkhurst, 1978; Mott et al., 1982).

Amphistomaty may also be related to leaf thickness because having only abaxial stomata would result in less intercellular diffusion throughout the thick mesophyll tissue (Mott et al., 1982). Studies in Mediterranean plants (Rhizopoulou and Psaras, 2003; Yiotis et al., 
2006) and American Southwest plants show correlation between amphistomaty and leaf thickness, measured by leaf mass per area (LMA). There is a slight trend towards amphistomaty with increasing leaf thickness (Mott et al., 1982).

LMA, or the inverse of specific leaf area (SLA), is also a common measurement used to analyze leaf morphology. It has long been established that a higher LMA is related to denser leaf tissue and thicker cuticles or epidermal layers (Beaulieu et al., 2008). Denser leaf tissue results in less intercellular air space from which water can evaporate. The presence of thick, waxy cuticles on leaf surfaces also decreases evaporation rates, helping a plant adapt to drier conditions. Species from warmer, xeric environments frequently possess denser leaf tissue and thicker cuticles, hence a higher LMA, than those from cooler, mesic environments (Parkhurst, 1978). A global survey of species' LMA shows that higher temperatures and lower rainfalls are associated with higher LMA (Wright et al., 2004). A combination of certain LMA values and stomatal traits may reflect a species' pre-adaptation to a given environment.

Plant adaptation to an environment and ability to thrive often depends on water requirements, but existing studies on water requirements of specific landscape plants is lacking (Niu et al., 2006). Although precise irrigation models exist for many agricultural plants, the same has not been as widely developed for landscape ornamentals, partly due to high species diversity and mixed plantings (Beeson, 2005; Nouri et al., 2013). The University of California Cooperative Extension has compiled the irrigation water needs of 3,546 landscape species through consultation with the state's leading horticulturalists. 
The information is publicly available in the Water Use Classification of Landscape Plants (Costello and Jones, 2014) and is used for the purpose of analyzing urban tree water requirements in this study. Other sources of landscape plant requirements are available, including gardening books, instructional guides, and horticultural journals. However, most of these sources provide information based upon existing experience in cultivation of traditionally popular or otherwise common landscape plants. A method for determining an unfamiliar species' response to environmental stressor remains to be developed.

Urban areas are manufactured landscapes with a unique ecosystem that poses challenging conditions for many plants. Landscape plants are frequently selected for aesthetic purposes, and environmental suitability is a secondary concern. To maintain the success of urban plants and forests and to ensure their continued delivery of ecosystem services, the selection of appropriate species is a mandatory step. Improved understanding of plant physiology offers the opportunity to predict an unfamiliar species' suitability to a given habitat, eliminating the dependence on empirical evidence and restriction to familiar species.

The objective of this study is to assess relationships between leaf functional traits and species water usage to determine if a model can be created to predict water use of unfamiliar tree species. Functional traits, including stomatal length, stomatal density, and LMA, were sampled from seventy of the most common California urban tree species. Other potential explanations of species water usage, such as amphistomaty and 
phylogenetics, are also explored. The ability to appropriately select species suitable to urban landscapes is necessary for urban foresters, arborists, horticulturalists, and city planners to successfully establish healthy urban forests. 


\section{CHAPTER 2}

\section{Methods}

\subsection{Species Selection and Leaf Collection}

Tree species were selected from California's most common urban street trees (Ritter, 2011), with the focus on angiosperms and other broad-leaved species. Since many gymnosperms have leaves unsuitable for the protocol used on stomatal measurements, most gymnosperm species were omitted. A total of 70 species were sampled, with two gymnosperms and 68 angiosperms. Altogether, the 70 species represented 61 genera and 30 families.

Leaves were sampled from mature, healthy trees growing on the California Polytechnic State University, San Luis Obispo campus and the cities of Fremont, CA and San Luis Obispo, CA to represent the population of urban street trees in California's North and Central Coasts. For each species, fully expanded leaves were collected from three individual trees with seven leaves taken from each tree on the south-facing canopy side. The only exceptions are Erythrina caffra Thunb. $(\mathrm{n}=2)$ and Melia azedarach L. $(\mathrm{n}=1)$ due to low abundance of these species in the sampling areas. All leaves were retained in a refrigerator and sampled within three days for stomatal measurements and LMA.

\subsection{Stomatal Measurements and LMA}

Stomata were measured indirectly by making epidermal peels on both adaxial and abaxial leaf surfaces with clear nail varnish or top coat. If dirty (e.g. covered in soot), the leaf was washed and dried before application of nail varnish. The nail varnish was allowed to 
fully dry before being peeled off with tape to create epidermal peels containing stomatal imprints, with each peel being approximately $1 \mathrm{~cm}^{2}$. Three epidermal peels were made for each individual tree for a total of nine peels per species. For Erythrina caffra and Melia azedarach, more peels were made per tree to result in the same total number of peels for each species. Epidermal peels were viewed under a Zoe ${ }^{\mathrm{TM}}$ Flourescent Cell Imager (Bio Rad) digital microscope. Images of stomata were digitally captured then calibrated with a built-in micrometer in Image J 1.x (Laboratory for Optical and Computational Instrumentation, University of Wisconsin). Average stomatal length and density were taken by measuring length for seven randomly selected stomata and measuring the area occupied by seven randomly selected groups of 10 or more stomata.
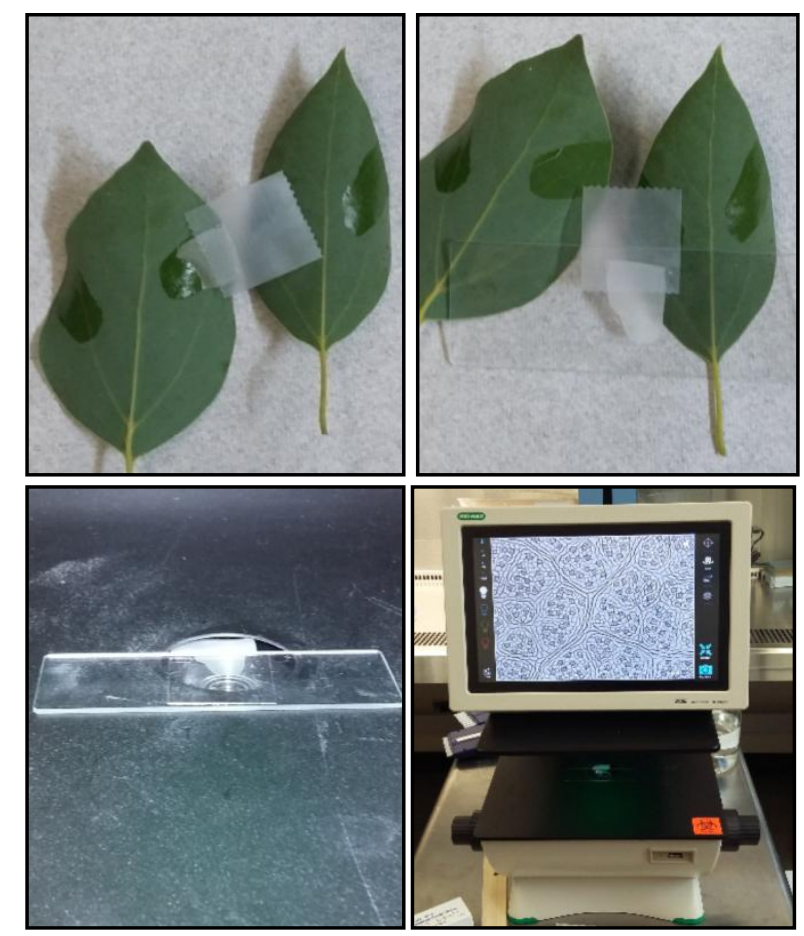

Figure 1. Process of Making Epidermal Peels. A) Clear nail varnish is applied to leaf surface. After air drying, the nail varnish is peeled off with adhesive tape starting from the leaf margin. B) The nail varnish (epidermal peel) containing stomatal imprints is placed on a glass microscope slide. C) The peel is covered with water and a cover slip before the slide is placed on the stage of a digital microscope. D) The Zoe ${ }^{\mathrm{TM}}$ Flourescent Cell Imager (Bio Rad) digital microscope with specimen on the stage and screen showing magnified stomata (about 700x). 


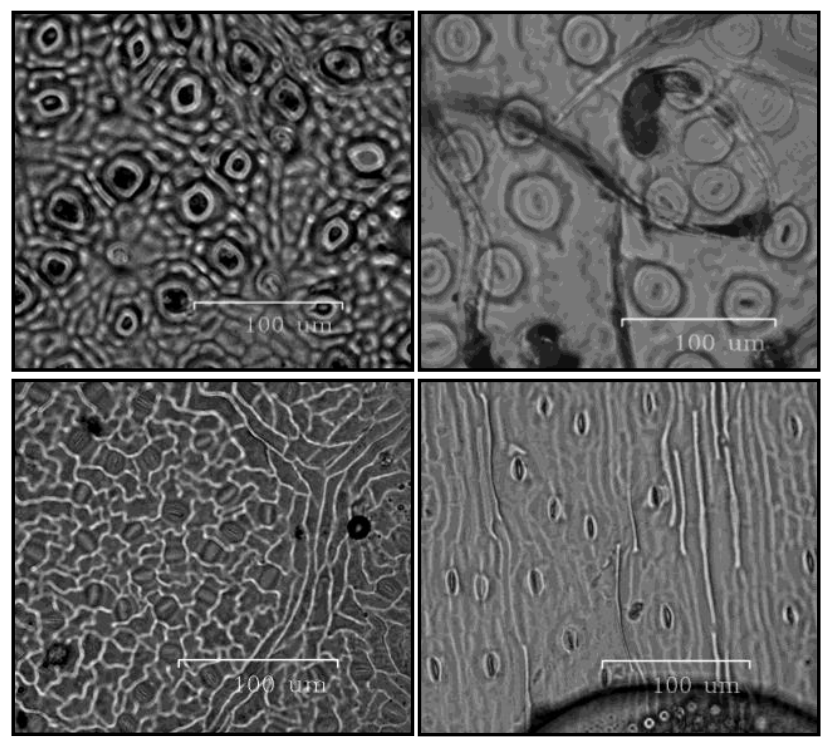

Figure 2. Images of Stomata as Viewed in Image J 1.x with Calibration Scale. Epidermal peels of stomata were magnified under the Zoe ${ }^{\mathrm{TM}}$ Flourescent Cell Imager and then digitally captured.

This epidermal peel sampling method worked best for broad, glabrous leaves. The usage of adhesive tape removed trichomes from leaves of certain species (e.g. Magnolia grandiflora L.), enabling production of clean epidermal peels with visible stomata. Some species with pubescent leaves (e.g. Grevillea robusta, Olea europea, Quercus suber)absorbed the applied nail varnish, could not be cleaned with adhesive tape, and failed to deliver usable epidermal peels and were thus, eliminated from this study. Future studies should strive to include these species with other sampling methods to provide an even more comprehensive analysis of California's urban trees.

Leaf mass per area (LMA) was obtained by hole-punching 10 leaf discs over three individual trees per species. Leaf discs ranged from $3.5-18 \mathrm{~mm}$ in diameter, depending on the species, and excluded the mid vein when possible. Leaf discs were dried at $52^{\circ} \mathrm{C}$ 
for one week then weighed. Average LMA per species was calculated by dividing dry leaf mass over fresh leaf area for each leaf disc.

\subsection{Water Usage and Phylogenetics}

Water usage data was retrieved from the Water Use Classification of Landscape Species (WUCOLS) (Costello and Jones, 2014) provided by the University of California Cooperative Extension. Horticultural experts evaluated 3,546 landscape species in reference to the evapotranspiration of a standard measurement $\left(\mathrm{ET}_{\mathrm{O}}\right)$. $\mathrm{ET}_{\mathrm{O}}$ is the estimated evapotranspiration of a well-irrigated, large field of four- to seven-inch tall cool-season turf grass and is a standard measure of irrigation required to maintain plant health. Landscape species are compared to $\mathrm{ET}_{\mathrm{O}}$ and classified as having very low $(<10 \%$ of $\left.\mathrm{ET}_{0}\right)$, low (10-30\% of $\left.\mathrm{ET}_{0}\right)$, medium (40-60\% of $\left.\mathrm{ET}_{0}\right)$, or high (70-90\% of $\left.\mathrm{ET}_{0}\right)$ water needs. A species' irrigation water needs can vary from region to region, so the state of California is divided into six regions based upon climate zones in WUCOLS. For the purposes of this study, water needs of all tree species are based upon Region 1 (North and Central Coast) as all trees were sampled from sites in this region. Because there are very few tree species included in this study that have very low or high water needs (less than 10 species), high water use species were reassigned to medium usage and very low water use species were reassigned to low water use. This helps the statistical analysis but may obscure details in the conclusions and increase variation within each water usage group. 


\subsection{Data Analysis}

\subsubsection{Trait Analysis}

Pairwise trait comparisons between stomatal length, stomatal density, and LMA were analyzed with Pearson's product-moment correlation. No assumptions are made in terms of independent and dependent variables as all data result from observational measurements. The arrangement of variables on graph axes does not indicate independence or dependence but rather, is arbitrary or based upon the questions asked. To test for significant trait differences between low and medium water use tree species, Welch's t-test was utilized as sample sizes are roughly equal but variance is not. Upon closer data inspection, a relationship between stomatal distribution (amphistomatous vs. hypostomatous) and water usage (low vs. medium) was observed, so a chi-square test for independence was performed to assess the significance of the relationship between the two variables. All tests were conducted at alpha levels of 0.05 .

\subsubsection{Predictive Model}

One objective of this study is to create a model for predicting tree species water use based upon functional traits, so a model was created with logistic regression. Logistic regression predicts the probability of a binary dependent variable as explained by one or more independent variables. In this study, the sole significant independent variable, LMA, as shown by t-test results, was used to predict the probability of a tree species to have low water usage. 


\subsubsection{Phylogenetic Analysis}

A phylogenetic tree of all 70 tree species was created (Phylomatic v3) onto which functional traits and water usage were hand-mapped in Interactive Tree of Life (iTOL v4) (developed by Letunic and Bork, 2019) to aid visual comprehension of data distribution. The phylogenetic tree was also used for independent contrasts using the APE (Paradis and Schliep, 2018) and GEIGER (Harmon et al., 2008) packages in R (R Core Team, 2018). Independent contrasts account for the non-independence of species in analysis for significant correlated trait evolution. Consideration of phylogeny allows for accurate conclusions on whether existing traits are results of phylogenetic inertia or responses to natural selection (Felsenstein, 1985). 


\section{CHAPTER 3}

\section{Results}

\subsection{Leaf Functional Traits and Water Usage across Species}

A total of 70 species were sampled and measured for mean stomatal length, mean stomatal density, and mean LMA (Fig. 3). Sixteen species were amphistomatous and 54 species were hypostomatous. Stomata of amphistomatous species were similar in length and density on both adaxial and abaxial surfaces (Figure 4). For the following analyses, abaxial stomata were used for all species unless otherwise noted.

Two species from the Myrtaceae had the highest mean stomatal length (Metrosideros excelsa Sol. ex Gaertn., Eucalyptus globulus Labill.), and one species in the same family had lowest mean stomatal length (Melaleuca linariifolia Sm.). Five out of the 10 species with the lowest mean stomatal length are represented by species in the Sapindaceae (Koelreuteria bipinnata Franch., Acer palmatum Thunb., K. elegans (Seem.) A.C.Sm., K. paniculata Laxm., Aesculus californica (Spach) Nutt.) (Fig. 3).

As predicted by the negative correlation between stomatal length and stomatal density (Beaulieu et al., 2008), species with higher mean stomatal lengths are generally associated with lower stomatal densities and vice versa. The species with some of the lowest mean stomatal lengths (Melaleuca linariifolia, Koelreuteria bipinnata, Acer palmatum, K. elegans) are amongst the top five species with the highest stomatal density. Species with very high mean stomatal lengths (Metrosideros excelsa, Eucalyptus globulus) are in the low end of the mean stomatal density distribution (Fig. 3). 
Eight of the 12 species with the highest mean LMA are from the Myrtaceae. Species with higher mean LMA also tend to have lower water usage (e.g. Phoenix canariensis Hort. ex Chabaud, Metrosideros excelsa, Eucalyptus globulus, Ceratonia siliqua L.), with the exception of Aesculus californica, which has the lowest mean LMA out of all species sampled (Fig. 3).

Species water usage (low vs. medium) tends to be the same within each clade, such as low water usage for most members of the Myrtaceae and medium water usage for all members of the Rosaceae (Fig. 3). Foliar longevity (deciduous vs. evergreen) is more varied within clades than water usage (Fig. 3) but may further explain differences in species water usage in addition to leaf functional traits. 


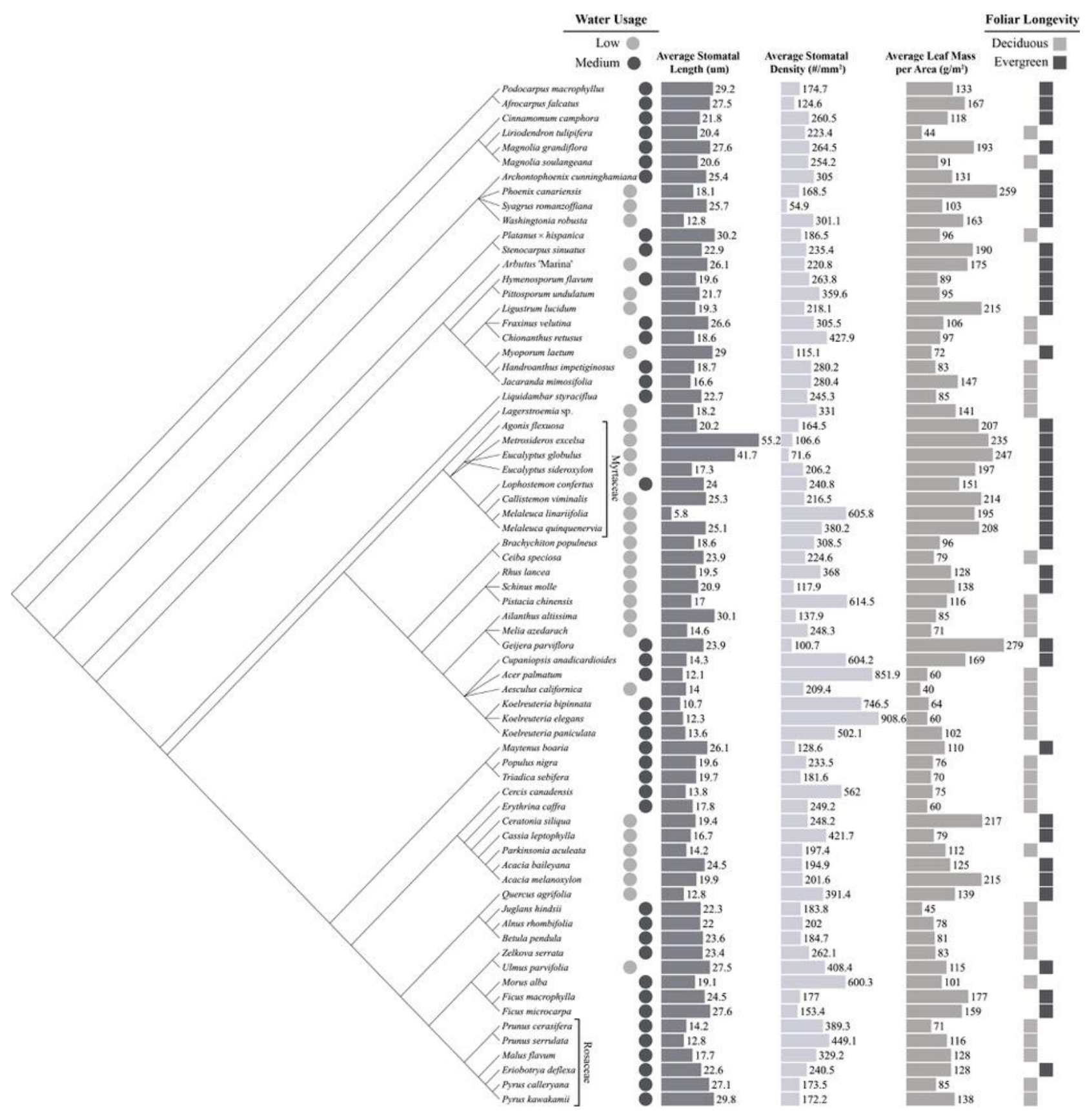

Figure 3. Phylogeny of All Species and Traits. Phylogenetic relationship of 70 tree species and distribution of water usage, foliar longevity, and all leaf functional traits measured (mean abaxial stomatal length (um), mean abaxial stomatal density $\left(\# / \mathrm{mm}^{2}\right)$, and mean LMA $\left(\mathrm{g} / \mathrm{m}^{2}\right)$ ). Values for leaf functional traits appear randomly distributed within clades, but water usage tends to be the same within each clade. Some correlation may exist between water usage and foliar longevity. 


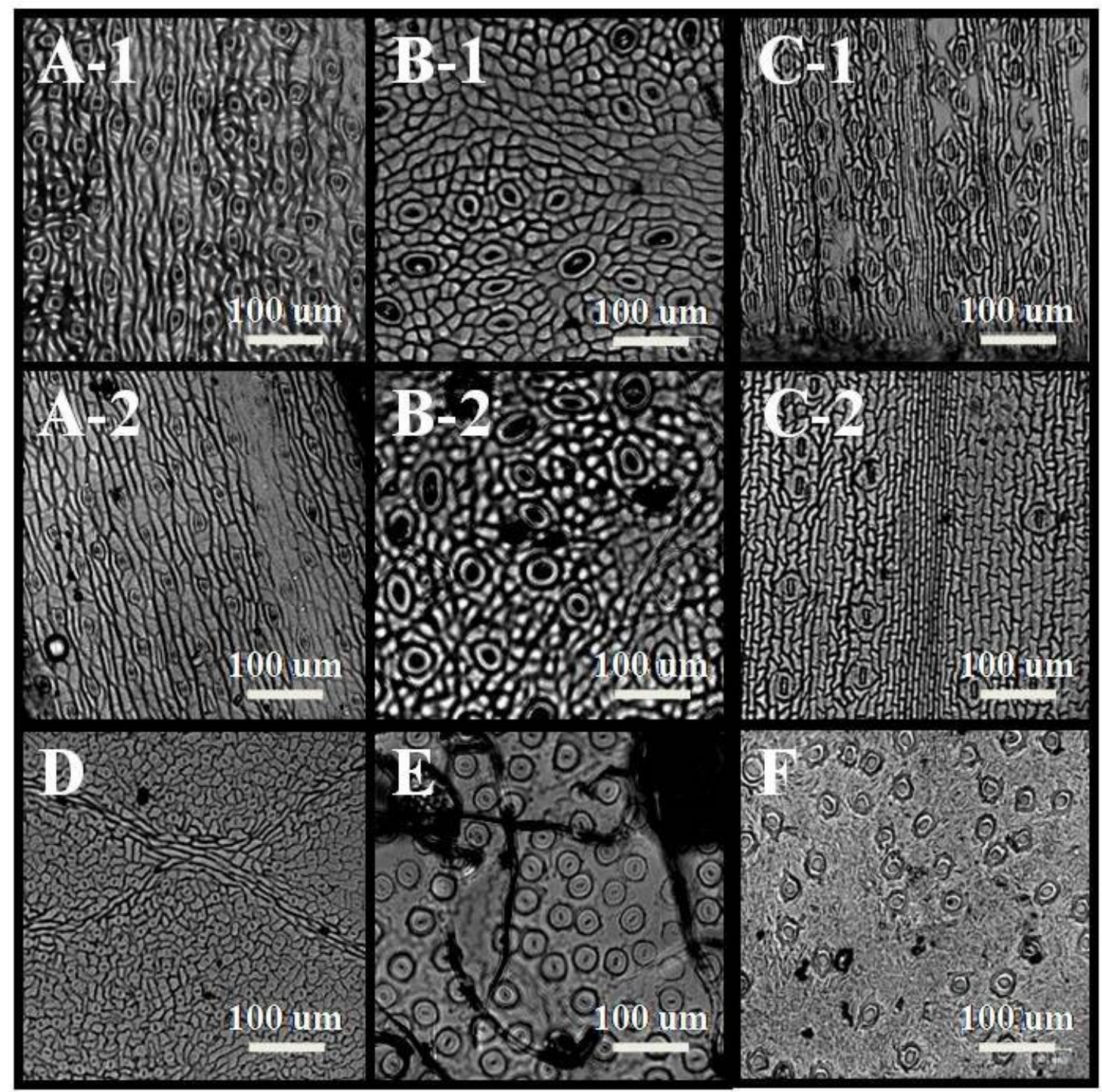

Figure 4. Microscope Images of Stomatal peels. Pictures show abaxial stomata (ABS) and adaxial stomata (ADS) for selected amphistomatous and hypostomatous species. A1: ABS Acacia dealbata. A-2: ADS A. dealbata. B-1: ABS Eucalyptus globulus. B-2: ADS E. globulus. C-1: ABS Syagrus romanzoffiana. C-2: ADS S. romanzoffiana. D: ABS Acer palmatum. E: ABS Magnolia grandiflora with trichomes. F: ABS Ficus microcarpa. Amphistomatous species (A-C) have very similar stomata on both leaf surfaces.

\section{$\underline{3.2 \text { Correlations between Leaf Functional Traits }}$}

Three pairwise relationships of leaf functional traits were analyzed. Correlation supports existing research (Beaulieu et al., 2008) that mean stomatal length and density are significantly negatively correlated $(\mathrm{r}=0.597, P<0.0001)($ Fig. 5), and this is the strongest 
correlation among all pairwise comparisons. Mean LMA slightly increases with increasing mean stomatal length, but the correlation is less significant $(r=0.303$, $P=0.0103$ ) (Fig. 6). There is a significant negative correlation between mean LMA and mean stomatal density (r=0.277, $P=0.0200)$ (Fig. 7).

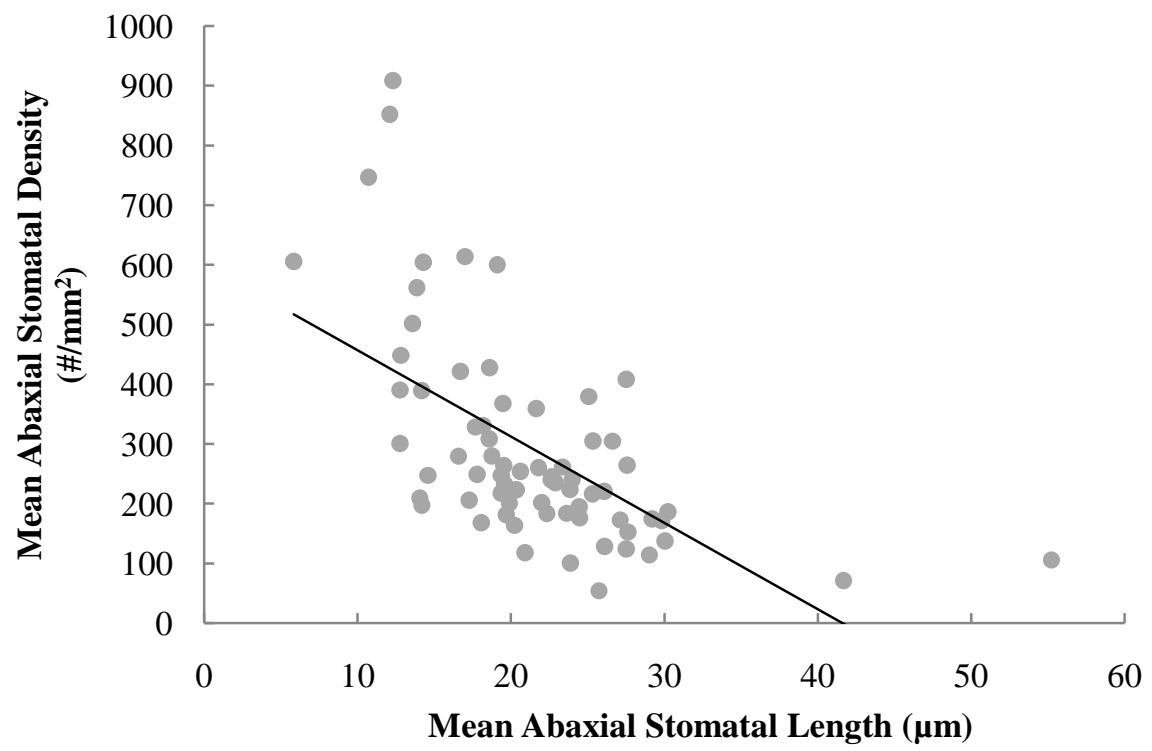

Figure 5. Relationship Between Mean Abaxial Stomatal Length $(\mu \mathrm{m})$ and Mean Abaxial Stomatal Density $\left(\# / \mathbf{m m}^{2}\right)$ across 70 Tree Species. As mean stomatal length increases, mean stomatal density decreases $(r=0.597, P<0.0001)$. 


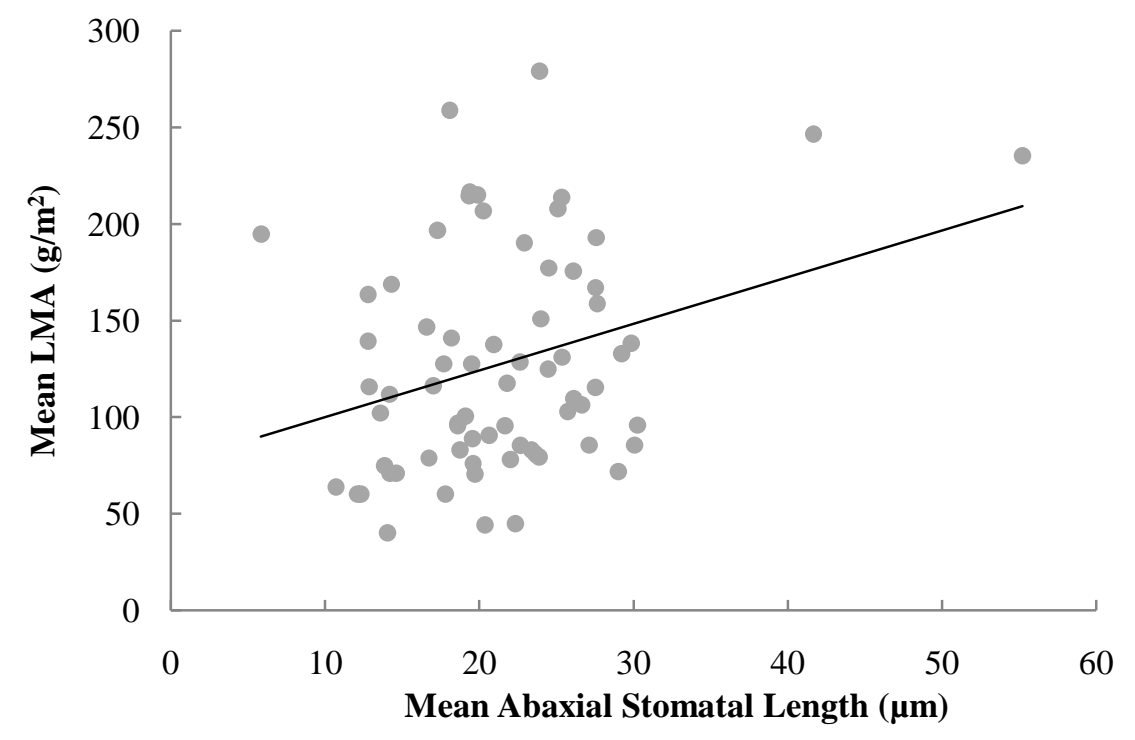

Figure 6. Relationship Between Mean Abaxial Stomata Length and LMA across 70 Tree Species. As mean stomatal length increases, there is a slight increase in mean LMA $(\mathrm{r}=0.303, P=0.0103)$.

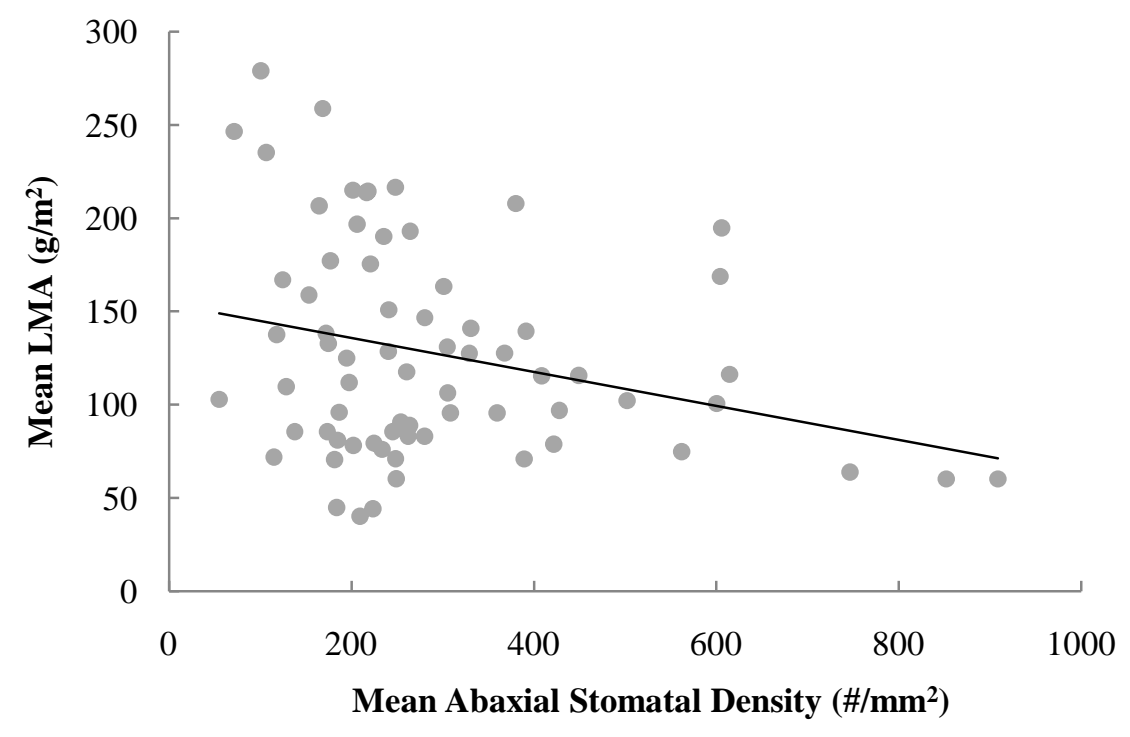

Figure 7. Relationship Between Mean Abaxial Stomatal Density and LMA across 70 Tree Species. As mean stomatal density increases, mean LMA decreases $(\mathrm{r}=0.277, P=$ $0.0200)$.

\subsection{Comparison by Water Usage}

All species sampled were divided into low water usage $(n=30)$ and medium water usage $(n=40)$ categories. Mean stomatal length is not statistically different between the two 
groups, and mean stomatal density is slightly, but insignificantly, higher in the medium water usage group (Fig. 8). Mean LMA is significantly different between the two groups, with low water usage trees having an average LMA $12.3-65.6 \mathrm{~g} / \mathrm{m}^{2}$ greater than medium water usage trees (Fig. 8).

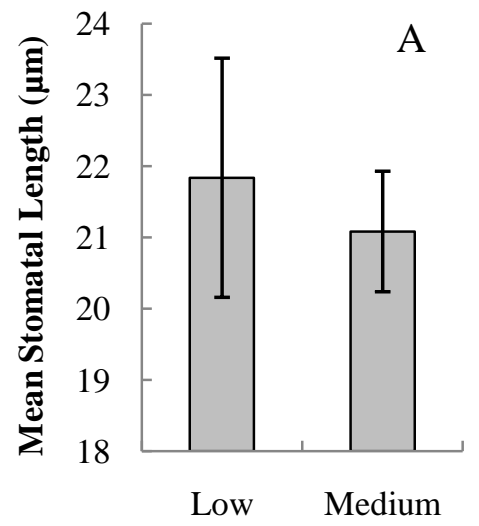

Water Use Category

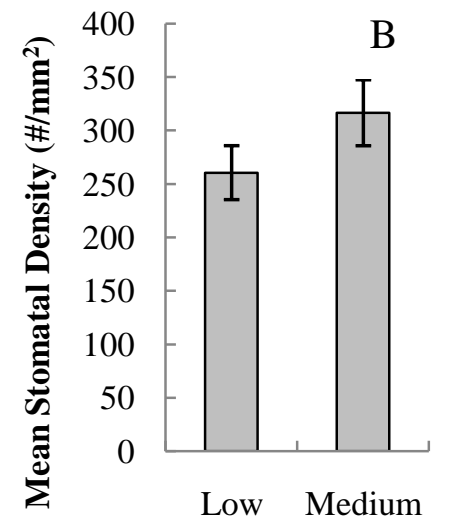

Water Use Category

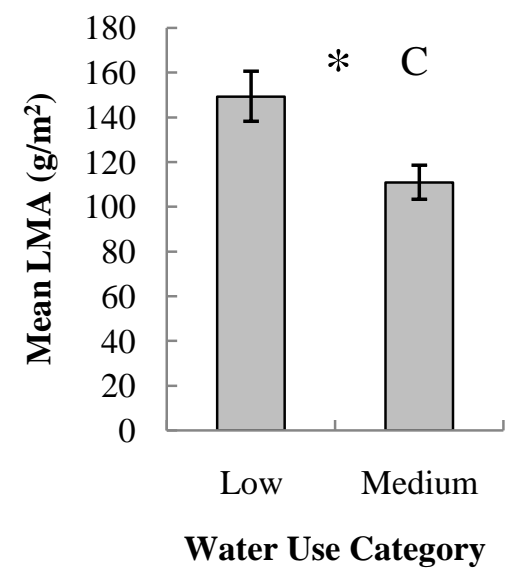

Figure 8. Comparisons of Various Leaf Morphological Traits of Trees with Low (n $=30)$ and Medium $(\mathbf{n}=40)$ Water Usage. Error bars show standard error. Fig. 8A. Average stomatal lengths are very similar for the two water usage groups and show no significant difference $(\mathrm{t}=-0.401, P=0.690)$. Fig. 8B. Average stomatal density is slightly higher in medium water usage trees, but statistical analysis shows no significant difference $(\mathrm{t}=-1.34, P=0.185)$. Fig. $8 \mathrm{C}$. Average LMA is significantly higher in low water usage trees compared to medium water usage trees $(\mathrm{t}=2.94, P=0.00450)$. * denotes statistical significance. 
A logistic regression model was created to predict species water usage (low or medium) based upon leaf functional traits. Results showed that only average LMA is significant and should be included in the model, as can be expected from the conclusions of the previous t-tests (Fig. 8), and produce the following predictive equation:

$\log$ odds water usage $($ Low/Medium $)=-1.94+0.0129($ mean LMA $)$

Since we sampled species for the presence of stomata on both adaxial and abaxial surfaces, we conducted an analysis to examine if stomatal distribution on both leaf surfaces is related to water usage. Results show that amphistomatous species are more likely than hypostomatous species to be low water usage (Fig. 9).

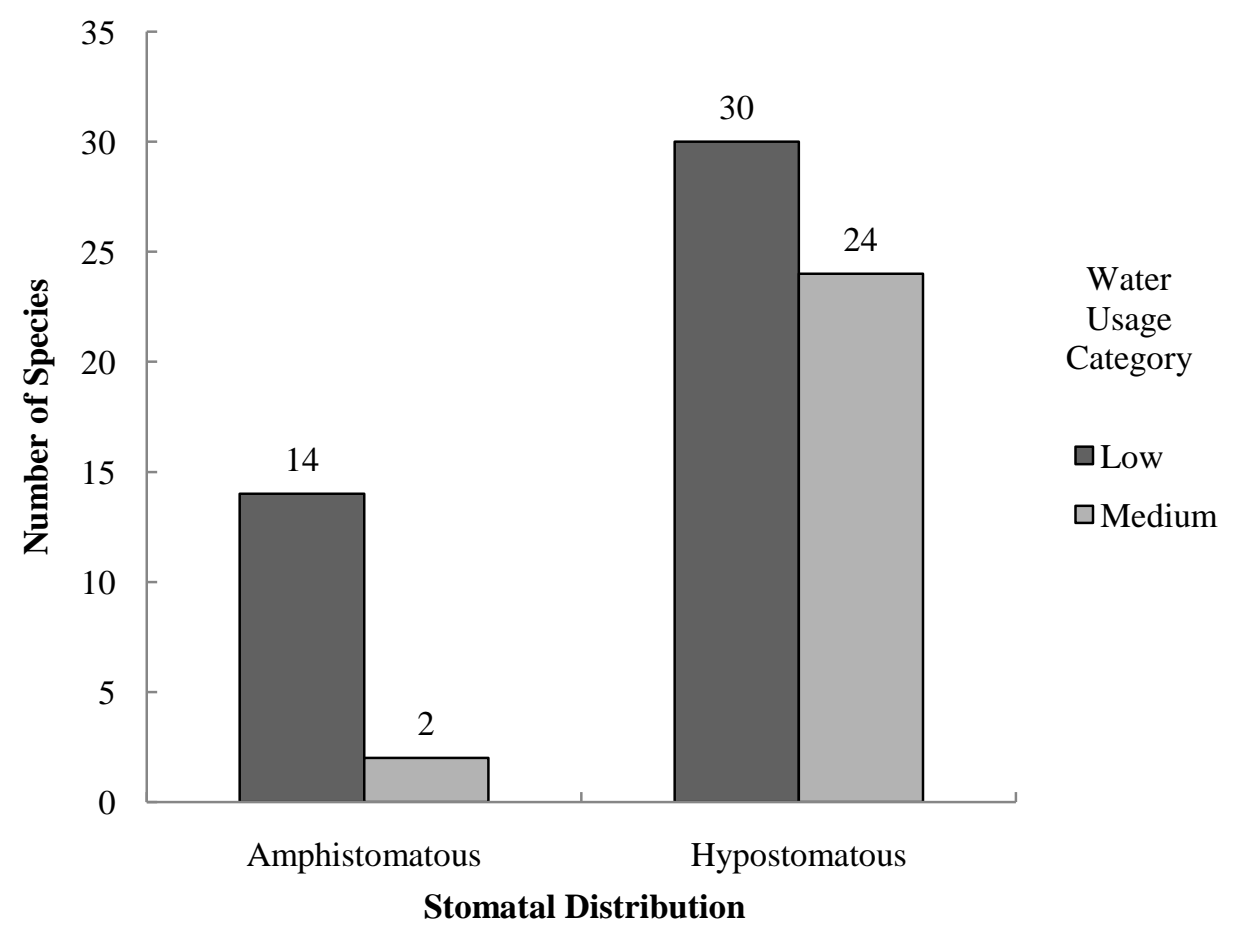

Figure 9. Comparison of Water Usage for Amphistomatous and Hypostomatous Tree Species. Amphistomatous species contain asignificantly lower proportion of medium water usage species than hypostomatous species (Yate's chi-square $=4.11, \mathrm{df}=$ $1, P=0.0426)$. 


\subsection{Phylogenetic Analysis}

As previously demonstrated, relationships between all functional traits are significant, and they remain significant after incorporating phylogenetic relationships with the exception of mean stomatal density and mean LMA (Table 1). A simple correlation between the two traits is significant $(\mathrm{r}=-0.278, P=0.0200)$, but significance is lost with independent contrasts $(\mathrm{r}=-0.0701, P=0.567)$ (Table 1). Each pairwise relationship between functional trait and water usage was not significant other than the significant correlation between mean LMA and water usage $(\mathrm{r}=-0.336, P=0.00449)$ (Table 1). However, accounting for phylogenetic relationships results loss of the significant relationship between the two traits $(\mathrm{r}=-0.134, P=0.273)$ (Table 1$)$.

Table 1. Pairwise Trait Comparisons Using Correlation and Independent Contrast. Relationships between stomatal density \& LMA and LMA \& water usage are significant with correlation but lose significance with independent contrasts.

\begin{tabular}{|c|c|c|c|c|c|c|c|c|}
\hline \multirow[b]{2}{*}{ Traits } & \multicolumn{4}{|c|}{ Correlation } & \multicolumn{4}{|c|}{ Independent Contrast } \\
\hline & $\mathrm{t}$ & $\mathrm{df}$ & $P$ & $\mathrm{r}$ & $\mathrm{t}$ & $\mathrm{df}$ & $P$ & $\mathrm{r}$ \\
\hline $\begin{array}{l}\text { stomatal length } \mathrm{x} \\
\text { stomatal density }\end{array}$ & -6.15 & 68 & $<0.001 *$ & -0.598 & -5.48 & 67 & $<0.001 *$ & -0.556 \\
\hline $\begin{array}{l}\text { stomatal length } x \\
\text { LMA }\end{array}$ & 2.64 & 68 & $0.0103^{*}$ & 0.305 & 1.84 & 67 & 0.0700 & 0.219 \\
\hline $\begin{array}{l}\text { stomatal density } \\
\mathrm{x} \text { LMA }\end{array}$ & -2.38 & 68 & $0.0200^{*}$ & -0.278 & -0.576 & 67 & 0.5666 & -0.0701 \\
\hline $\begin{array}{l}\text { stomatal length } x \\
\text { water usage }\end{array}$ & -0.431 & 68 & 0.668 & -0.0522 & 0.681 & 67 & 0.4979 & 0.0830 \\
\hline $\begin{array}{l}\text { stomatal density } \\
\mathrm{x} \text { water usage }\end{array}$ & 1.339 & 68 & 0.185 & 0.160 & -0.393 & 67 & 0.6953 & -0.0480 \\
\hline $\begin{array}{l}\text { LMA x water } \\
\text { usage }\end{array}$ & -2.94 & 68 & $0.00449 *$ & -0.336 & -1.11 & 67 & 0.273 & -0.134 \\
\hline
\end{tabular}




\section{CHAPTER 4}

\section{Discussion}

\section{$\underline{\text { 4.1 Pairwise Trait Comparisons }}$}

The results from pairwise trait correlations provide predictive relationships between leaf functional traits that may be useful in-field characteristics. Especially noteworthy is the significant negative correlation between mean stomatal length and density (Fig 6), as predicted by previous research (Beaulieu et al., 2008). It is intuitive that as stomatal length increases, the number of stomata that can be supported per unit surface area decreases. The original hypothesis that species with denser arrangements of smaller stomata have lower water usage (Hetherington and Woodward, 2003) is not supported by results of this study. There is no statistically significant difference in stomatal length between low and medium water use species (Fig. 8), and stomatal density is insignificantly higher in medium water use species (Fig. 8), contradictory to initial expectations.

The positive relationship between mean stomatal length and mean LMA, although significant, is relatively weak as the data are highly scattered (Fig 6). In regards to mean stomatal density and mean LMA, the latter trait is widespread for species with mean stomatal densities of 600 stomata/mm $\mathrm{mm}^{2}$ or fewer (Fig 7). However, a few species appear to drive the significant negative correlation between mean stomatal density and mean LMA, as shown by the three species with mean stomatal densities above 700 stomata/mm $\mathrm{mm}^{2}$ and with relatively low LMA's of about $75 \mathrm{~g} / \mathrm{m}^{2}$ (Fig 7). All three of these species are members of the Sapindaceae, and further phylogenetic clusters may exist 
within this trend. Application of logistic regression to predict water usage based upon LMA produced a model with low predictive power.The model's predictive power is too low for practical applications, and further research is needed to produce a more accurate and useful model.

\section{$\underline{4.2 \text { Phylogenetics }}$}

Upon incorporation of phylogenetic relationships, significance in the relationship between mean stomatal density and mean LMA was lost (Table 1), implying that basal divergences within the phylogeny are involved. It is speculated that although a significant relationship exists for all 70 species combined, closer inspections of phylogenetic groupings may reveal loss of significance within each phylogenetic group (Fig. 3) Upon reconsideration of the relationship between mean stomatal density and mean LMA at the taxonomic level of order (and super order for Magnoliids), clear trends between the traits are weakened (Fig. 10). At mean stomatal densities of $200-300$ stomata $/ \mathrm{mm}^{2}$, members of the Fabales display a wide range of mean LMA from about $60-210 \mathrm{~g} / \mathrm{m}^{2}$. Similar observations of relatively low stomatal density ranges yet widespread LMA can be made for the Arecales and the Magnoliids. Members of the Lamiales appear tightly clustered at low stomatal densities and low LMA's. Within the Myrtales and Rosales, a slight negative correlation between stomatal density and LMA is observed. In the Sapindales, apart from a single species (Geijera parviflora Lindl.) with low mean stomatal density and high LMA, all species have relatively tightly clustered LMA values but a wide range of stomatal densities. (Fig. 10). These observations may provide insight into the loss of significance after incorporation of phylogenetics. 


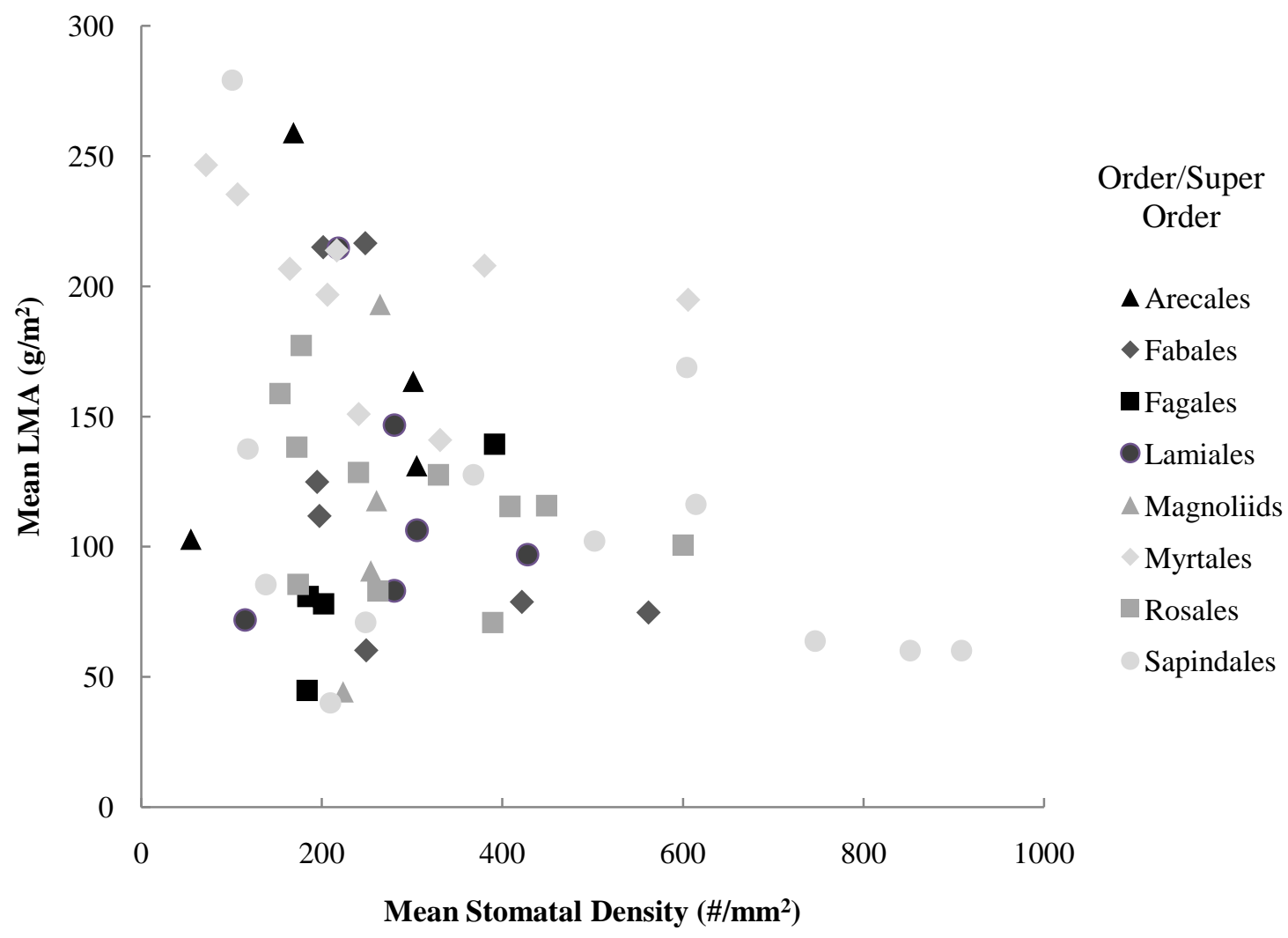

Figure 10. Scatterplot of Mean Stomatal Density $\left(\# / \mathrm{mm}^{2}\right)$ and Mean LMA $\left(\mathrm{g} / \mathrm{m}^{2}\right)$ for Orders $(n=7)$ and Super Orders $(n=1)$ with More Than Three Species. Some orders show more randomness in the spread of datapoints (e.g. Arecales, Lamiales, Magnoliids), but other orders are show clearer patterns (e.g. Rosales, Sapindales).

Basal divergences may also be causing the observed correlations between LMA and water usage (Table 1), rather than response to environmental factors. Most members of the Arecales, Fabales, and Myrtales have low water usage regardless of LMA (Fig. 3). On the other hand, most if not all members of the Fagales, Lamiales, Magnoliids, and Rosales have medium water usage regardless of LMA (Fig. 3).

\subsection{Stomatal Distribution on Both Leaf Surfaces}

Phylogenetics provides some predictive capability of species' water usage, but stomatal distribution may be a morphological predictive tool. Fifteen out of the 70 species sampled 
are amphistomatous, and statistical analysis concludes that amphistomatous species are more likely to be low water usage compared to hypostomatous species (Fig. 9). These were unanticipated results, but may provide a morphological clue on species' drought tolerance. Previous studies suggest that amphistomaty is derived from the ancestral trait of hypostomaty and is more likely in xeric than in mesic environments (Parkhurst, 1978). It is suggested that amphistomaty is advantageous in xeric, high-light environments where carbon diffusion is the only limiting factor to photosynthesis (Mott et al., 1982).

Amphistomaty may also be related to leaf thickness because having only abaxial stomata would result in less intercellular diffusion throughout the thick mesophyll tissue (Mott et al., 1982). Past studies in Mediterranean plants (Rhizopoulou and Psaras, 2003) and American Southwest plants (Yiotis et al., 2006) show a trend towards amphistomaty with increasing LMA. Analysis of the 70 tree species sampled in this study supports the aforesaid research with amphistomatous species having a significantly higher mean LMA than hypostomatous species $(\mathrm{t}=12.231, P<0.0001)$ (Fig. 11). A global study on more than 2,000 plant species showed that species with a higher LMA are more likely to be found in warm, xeric environments (Wright et al., 2004). Thus, if a higher LMA is associated with amphistomaty and warm, xeric conditions, than amphistomaty should be also associated with the same climatic conditions. 


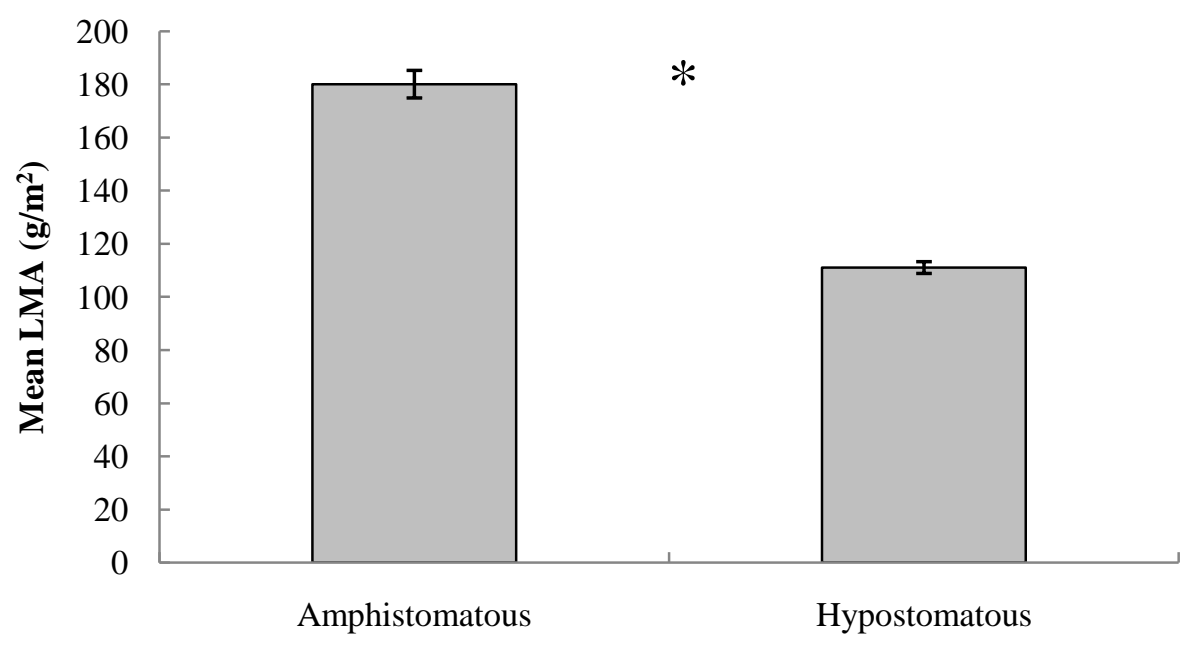

Stomatal Distribution

Figure 11. Comparison of Mean LMA $\left(\mathrm{g} / \mathrm{m}^{2}\right)$ between Amphistomatous and Hypostomatous Individuals of all Species Sampled. Amphistomatous species have a higher mean LMA than hypostomatous species (95\% confidence interval $($ amphistomatous-hypostomatous $\left.)=57.91-80.15 \mathrm{~g} / \mathrm{m}^{2}\right)(\mathrm{t}=12.231, \mathrm{df}=220, P<$ 0.0001).

\subsection{Other Explanations for Differences in Water Usage}

LMA, phylogenetic relationships, and amphistomaty can partially explain differences in water usage for tree species, but many potential factors still exist and remain to be explored. One factor commonly observed in all tree species is leaf longevity, often broadly categorized as evergreen or deciduous. Based upon observations in the 70 sampled species (Fig. 3), there is reason to expect that leaf longevity may be related to water usage. It must be brought to attention that deciduous refers to both winter and summer deciduous (Aesculus californica), with the latter being more drought adapted. Otherwise, it appears that deciduous species are more likely to be of medium than low water usage. Statistical comparisons of water usage for evergreen and winter deciduous species lack significant results (Yate's chi-square $=2.19, P=0.139)($ Fig. 12), so leaf longevity alone cannot explain variation in water usage. 
Another factor worthy of consideration is species' native ranges, which influence the evolutionary development of traits such as leaf longevity and water usage. For example, all species sampled from the Myrtaceae originate from Australia, are evergreen, and have low water usage (Fig. 3). Most species native to Northern temperate regions (e.g. Alnus rhombifolia Mill., Fraxinus velutina L., Prunus serrulata Lindl.) are deciduous and have medium water usage (Fig. 3).

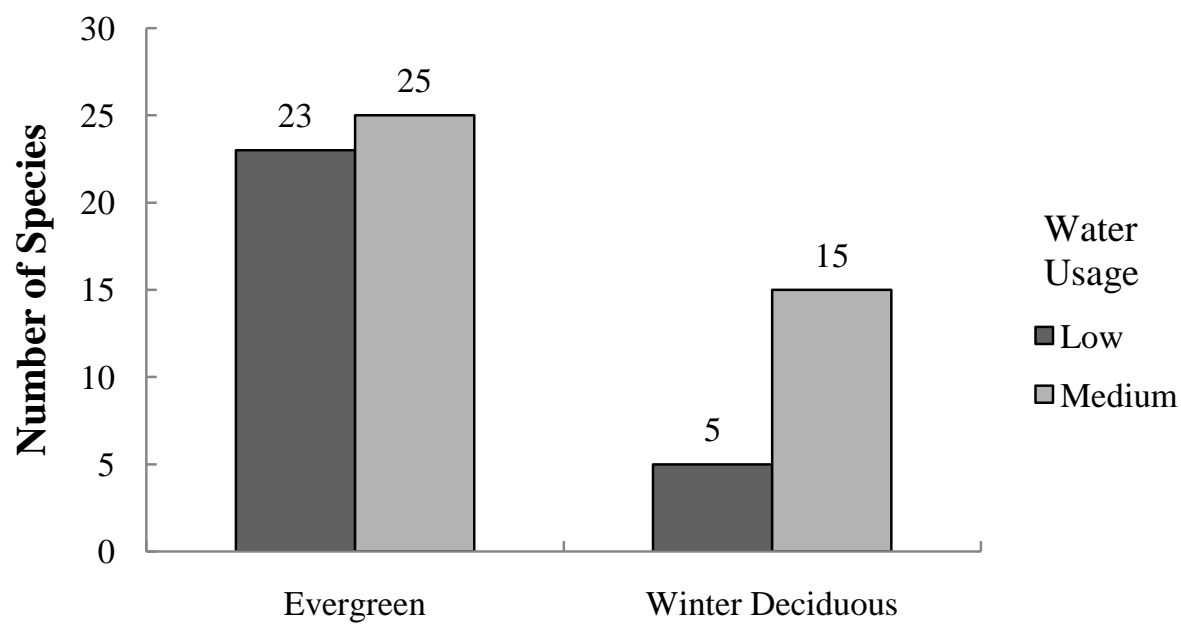

\section{Foliar Longevity}

Figure 12. Relationship between Foliar Longevity (evergreen or winter deciduous) and Water Usage (low or medium). Evergreen species have $\sim 50 \%$ chance of being low water use, compared to the $33 \%$ of deciduous species, but differences are insignificant (Yate's chi-square $=2.19$, df $=1, P=0.139$ ). 


\section{CHAPTER 5}

\section{Conclusion \& Recommendations}

In conclusion, LMA is significantly higher for low than medium water usage tree species in California's urban forests. However, usage of LMA to predict water usage for an unfamiliar tree species should be approached with caution as underlying phylogenetic relationships have a greater impact on water usage. It is somewhat surprising that stomatal length and density aren't significantly associated with water usage as suggested by previous studies (Hetherington and Woodward, 2003), but the result showing strong, negative correlation between these two traits supports existing research (Beaulieu et al., 2008). Amphistomaty is more likely to be observed in high LMA and low water use species, and may provide a useful diagnostic tool in the field. Broader observations of leaf longevity and species native ranges should not be ignored when considering species water use requirements.

The methods of this study limit conclusions to mature tree species in North and Central coastal California. A more wide-ranging study would sample species from all six WUCOLS regions of California, and can demonstrate whether or not the same results remain consistent from one geographical region to another. Furthermore, many tree species were excluded from the study due to technical difficulties in making epidermal peels to analyze stomata. Future research should aim to include these species, such as gymnosperms and pubescent-leaved trees, to produce more comprehensive results. This would also increase the number of water usage groups to include very low and high water usage for a total of four categories, which may provide a better fitting model. This study 
also assumes no seasonal and geographic variation in leaf functional traits (after Casson and Gray, 2008), but some traits (e.g. LMA) may vary slightly as leaves transition from dormancy to full maturity.

A combination of LMA, phylogenetic relationships, stomatal distribution, and foliar longevity should be considered when speculating on the water usage of tree species. Based upon findings in this study, candidates for low water landscapes are species from the Anacardiaceae, Arecaceae, Fabaceae, and Myrtaceae. Many of these species possess amphistomaty and evergreen leaves, in addition to originating from warmer, more xeric environments. The combination of these traits and the expected management routine will influence tree species establishment and success under long-term low water conditions. 


\section{REFERENCES}

Beaulieu, J.M., Leitch, I.J., Patel, S., Pendharkar, A., Knight, C.A. 2008. Genome size is a strong predictor of cell size and stomatal density in angiosperms. New Phytologist, 179, 975-986.

Beeson, R.C. 2005. Modeling irrigation requirements for landscape ornamentals. Horttechnology, 15, 18-22.

Bosabalidis, A.M., Kofidis, G. 2002. Comparative effects of drought stress on leaf anatomy of two olive cultivars. Plant Science, 163(2), 375-379.

Brenzel, K.N. (Ed.). 2012. Sunset Western Garden Book, $9^{\text {th }}$ ed. 2012. New York, NY: Time Home Entertainment Inc.

Cameron, R.W.F. 2003. Plants in the environment: amenity horticulture. In:Thomas, B., Murphy, D., Murray, B. (Eds.), The Encyclopedia of Applied Plant Sciences. Elsevier Science Ltd, London, 735-742.

Casson, S., Gray, J.E. 2008. Influence of environmental factors on stomatal development. New Phytologist, 178(1), 9-23.

Costello, L.R., Jones, K.S. 2014. WUCOLS IV: Water Use Classification of Landscape Plants.California Center for Urban Horticulture, University of California, Davis. http://ucanr.edu/sites/WUCOLS/

Felsenstein, J. 1985. Phylogenies and the comparative method. The American Naturalist, 125(1), 1-15.

Hardy, J.P., Anderson, V.A.L.J., Gardner, J.S., 1995. Stomatal characteristics, conductance rations, and drought-induced leaf modifications of semiarid grassland species. Botanical Society of America, 82, 1-7.

Harmon, L.J., Weir, J.T., Brock, C.D., Glor, R.E., Challenger, W. 2008. GEIGER: Investigating evolutionary radiations. Bioinformatics 24:129-131.

Hetherington, A.M., Woodward, F.I. 2003. The role of stomata in sensing and driving environmental change. Nature, 424, 901-908.

Letunic, I., Bork, P. 2016. Interactive tree of life (iTOL) v3: an online tool for the display and annotation of phylogenetic and other trees. Nucleic Acids Research, 44(W1), W242W245.

McPherson, E.G., Xiao, Q., van Doorn, N.S., de Goede, J., Bjorkman, J., Hollander, A., 
Boynton, R.M., Quinn, J.F., Thorne, J.H., 2017. The structure, function and value of urban forests in California communities. Urban Forestry \&. Urban Greening, 28, 43-53.

McPherson, E.G., Berry, A.M., van Doorn, N.S. 2018. Performance testing to identify climate-ready trees. Urban Forestry \& Urban Greening, 29, 28-39.

Mott, K.A., Gibson, A.C., O'Leary, J.W. 1982. The adaptive significance of amphistomatic leaves. Plant, Cell, and Environment, 5, 455-460.

Niu, G., Rodriguez, D.S., Cabrera, R.I., McKenney, C., Mackay, W. 2019. Determining Water Use and Crop Coefficients in Five Woody Ornamental Plants. HortScience, 41, 1009A - 1009 .

Nouri, H., Beecham, S., Hassanli, A.M., Kazemi, F. 2013. Water requirements of urban landscape plants: A comparison of three factor-based approaches. Ecol. Eng., 57, 276284.

Ow, L.F., Yeo, T.Y., Sim, E.K. 2011. Identification of drought-tolerant plants for roadside greening - an evaluation of chlorophyll fluorescence as an indicator to screen for drought tolerance. Urban Forestry \& Urban Greening, 10(3), 177-184.

Paradis, E.,Schliep, K. 2018. ape 5.0: an environment for modern phylogenetics and evolutionary analyses in R. Bioinformatics $\mathrm{xx}$ : $\mathrm{xxx}-\mathrm{xxx}$.

Perry, B. 2010.Landscape Plants for California Gardens. Claremont, CA: Land Design Publishing.

Parkhurst, D.F. 1978. The adaptive significance of stomatal occurrence on one or both surfaces of leaves. Journal of Ecology, 66(2), 367-383.

R Core Team. 2018. R: A language and environment for statistical computing. $\mathrm{R}$ Foundation forStatistical Computing, Vienna, Austria. URL https://www.R-project.org/.

Rhizopoulou, S., Psaras, G.K., 2003. Development and Structure of Drought-tolerant leaves of the Mediterranean Shrub Capparisspinosa L. Annals of Botany, 92(3), 377-383.

Ritter, M. 2011. A Californian's Guide to Trees Among Us. Berkeley, CA: Heyday.

Sage, R.F. 2014. Stopping the leaks: new insights into $\mathrm{C}_{4}$ photosynthesis at low light. Plant, cell and environment, 37, 1037-1041.

Sternan, Nancy. 2007. California Gardener's Guide, Volume II. Franklin, TN: Cool Springs Press. 
Swoczyna, T., Kalaji, H.M., Pietkiewicz, S., Borowski, J. 2015. Ability of various tree species to acclimation in urban environments probed with the JIP-test. Urban Forestry \& Urban Greening, 14(3), 544-553.

Wright, I.J., Reich, P.B., Westoby, M., Ackerly, D.D., Baruch, Z., Bongers, F., et al. 2004. The worldwide leaf economics spectrum. Nature, 428, 821-827.

Xu, Z., Zhou, G. 2008. Responses of leaf stomatal density to water status and its relationship with photosynthesis in a grass. Journal of Experimental Botany, 59(12), 3317-3325.

Yiotis, C., Manetas, Y.,Psaras, G.K., 2006. Leaf and green stem anatomy of the drought deciduous Mediterranean shrub Calicotomevillosa (Poiret) Link.(Leguminosae). FloraMorphology, Distribution, Functional Ecology of Plants, 201(2), 102-107 


\section{APPENDIX A. STUDY DATA}

Table 2. Compiled Data for all 70 Tree Species Sampled. Species are listed in alphabetical order by genus name. Data include plant families, species names, the means of all leaf functional traits measured, water usage (both the original and reassigned values), and foliar longevity. Blank cells for adaxial stomatal measurements indicate that the species are hypostomatous.

\begin{tabular}{|c|c|c|c|c|c|c|c|c|c|c|}
\hline Family & Genus & Species & $\begin{array}{c}\text { Mean } \\
\text { Abaxial } \\
\text { Stomatal } \\
\text { Length } \\
(\mu \mathrm{m})\end{array}$ & $\begin{array}{c}\text { Mean } \\
\text { Adaxial } \\
\text { Stomatal } \\
\text { Length } \\
(\mu \mathrm{m})\end{array}$ & $\begin{array}{c}\text { Mean } \\
\text { Abaxial } \\
\text { Stomatal } \\
\text { Density } \\
\left(\# / \mathbf{m m}^{2}\right)\end{array}$ & $\begin{array}{c}\text { Mean } \\
\text { Adaxial } \\
\text { Stomatal } \\
\text { Density } \\
\left(\# / \mathbf{m m}^{2}\right)\end{array}$ & $\begin{array}{c}\text { Mean } \\
\text { Leaf } \\
\text { Mass } \\
\text { per } \\
\text { Area } \\
(\mathrm{g} / \mathrm{m} 2)\end{array}$ & $\begin{array}{c}\text { Water } \\
\text { Usage: } \\
\text { WUCOLS } \\
\text { Region } 1\end{array}$ & $\begin{array}{c}\text { Reassigned } \\
\text { Water } \\
\text { Usage }\end{array}$ & $\begin{array}{c}\text { Foliar } \\
\text { Longevity }\end{array}$ \\
\hline Fabaceae & Acacia & baileyana & 24.45 & 26.48 & 194.85 & 195.13 & 124.90 & $\mathrm{~L}$ & $\mathrm{~L}$ & Evergreen \\
\hline Fabaceae & Acacia & melanoxylon & 19.89 & 20.52 & 201.58 & 211.51 & 215.03 & VL & $\mathrm{L}$ & Evergreen \\
\hline Sapindaceae & Acer & palmatum & 12.09 & & 851.89 & & 60.13 & M & M & Deciduous \\
\hline Sapindaceae & Aesculus & californica & 14.04 & & 209.39 & & 40.06 & VL & $\mathrm{L}$ & Deciduous \\
\hline Podocarpaceae & Afrocarpus & falcatus & 27.53 & 28.37 & 124.63 & 112.76 & 167.00 & M & M & Evergreen \\
\hline Myrtaceae & Agonis & flexuosa & 20.25 & 23.33 & 164.50 & 105.27 & 206.68 & $\mathrm{~L}$ & $\mathrm{~L}$ & Evergreen \\
\hline Simaroubaceae & Ailanthus & altissima & 30.05 & & 137.88 & & 85.47 & VL & $\mathrm{L}$ & Deciduous \\
\hline Betulaceae & Alnus & rhombifolia & 22.01 & & 201.96 & & 78.11 & $\mathrm{H}$ & M & Deciduous \\
\hline Ericaceae & Arbutus & 'Marina' & 26.09 & & 220.82 & & 175.48 & $\mathrm{~L}$ & $\mathrm{~L}$ & Evergreen \\
\hline Arecaceae & Archontophoenix & cunninghamiana & 25.36 & & 305.01 & & 131.00 & M & M & Evergreen \\
\hline Betulaceae & Betula & pendula & 23.65 & & 184.75 & & 80.88 & $\mathrm{H}$ & M & Deciduous \\
\hline Malvaceae & Brachychiton & populneus & 18.59 & & 308.47 & & 95.58 & $\mathrm{~L}$ & $\mathrm{~L}$ & Evergreen \\
\hline Myrtaceae & Callistemon & viminalis & 25.33 & 24.93 & 216.52 & 243.30 & 213.77 & $\mathrm{~L}$ & $\mathrm{~L}$ & Evergreen \\
\hline Fabaceae & Cassia & leptophylla & 16.72 & & 421.68 & & 78.82 & $\mathrm{~L}$ & $\mathrm{~L}$ & Evergreen \\
\hline Malvaceae & Ceiba & speciosa & 23.87 & & 224.61 & & 79.37 & $\mathrm{~L}$ & $\mathrm{~L}$ & Deciduous \\
\hline
\end{tabular}




\begin{tabular}{|c|c|c|c|c|c|c|c|c|c|c|}
\hline Fabaceae & Ceratonia & siliqua & 19.37 & & 248.24 & & 216.56 & $\mathrm{~L}$ & $\mathrm{~L}$ & Evergreen \\
\hline Fabaceae & Cercis & canadensis & 13.85 & & 561.96 & & 74.76 & M & M & Deciduous \\
\hline Oleaceae & Chionanthus & retusus & 18.61 & & 427.88 & & 96.87 & M & M & Deciduous \\
\hline Lauraceae & Cinnamomum & camphora & 21.78 & & 260.54 & & 117.59 & M & M & Evergreen \\
\hline Sapindaceae & Cupaniopsis & anacardioides & 14.29 & & 604.19 & & 168.77 & M & M & Evergreen \\
\hline Rosaceae & Eriobotrya & deflexa & 22.63 & & 240.53 & & 128.49 & M & M & Evergreen \\
\hline Fabaceae & Erythrina & caffra & 17.80 & & 249.24 & & 60.23 & M & M & Deciduous \\
\hline Myrtaceae & Eucalyptus & globulus & 41.67 & 41.12 & 71.57 & 71.74 & 246.56 & $\mathrm{~L}$ & $\mathrm{~L}$ & Evergreen \\
\hline Myrtaceae & Eucalyptus & sideroxylon & 17.28 & 18.94 & 206.15 & 193.67 & 196.74 & $\mathrm{~L}$ & $\mathrm{~L}$ & Evergreen \\
\hline Moraceae & Ficus & microcarpa & 24.49 & & 177.01 & & 177.20 & M & M & Evergreen \\
\hline Moraceae & Ficus & macrophylla & 27.65 & & 153.44 & & 158.77 & M & M & Evergreen \\
\hline Oleaceae & Fraxinus & velutina & 26.64 & & 305.47 & & 106.28 & M & M & Deciduous \\
\hline Rutaceae & Geijera & parviflora & 23.89 & 22.77 & 100.72 & 133.45 & 279.11 & M & M & Evergreen \\
\hline Bignoniaceae & Handroanthus & impetiginosus & 18.74 & & 280.17 & & 83.03 & M & M & Deciduous \\
\hline Pittosporaceae & Hymenosporum & flavum & 19.55 & & 263.80 & & 88.80 & M & M & Evergreen \\
\hline Bignoniaceae & Jacaranda & mimosifolia & 16.57 & & 280.43 & & 146.63 & M & M & Deciduous \\
\hline Juglandaceae & Juglans & hindsii & 22.33 & & 183.82 & & 44.84 & M & M & Deciduous \\
\hline Sapindaceae & Koelreuteria & bipinnata & 10.70 & & 746.52 & & 63.77 & M & M & Deciduous \\
\hline Sapindaceae & Koelreuteria & elegans & 12.32 & & 908.63 & & 60.13 & M & M & Deciduous \\
\hline Sapindaceae & Koelreuteria & paniculata & 13.59 & & 502.06 & & 102.14 & M & M & Deciduous \\
\hline Lythraceae & Lagerstroemia & sp. & 18.19 & & 330.98 & & 140.92 & $\mathrm{~L}$ & $\mathrm{~L}$ & Deciduous \\
\hline Oleaceae & Ligustrum & lucidum & 19.34 & & 218.12 & & 214.53 & $\mathrm{~L}$ & $\mathrm{~L}$ & Evergreen \\
\hline Altingiaceae & Liquidambar & styraciflua & 22.66 & & 245.26 & & 85.43 & M & M & Deciduous \\
\hline Magnoliaceae & Liriodendron & tulipifera & 20.36 & & 223.42 & & 44.17 & M & M & Deciduous \\
\hline Myrtaceae & Lophostemon & confertus & 23.98 & & 240.78 & & 150.88 & M & M & Evergreen \\
\hline Magnoliaceae & Magnolia & grandiflora & 27.58 & & 264.46 & & 192.93 & M & M & Evergreen \\
\hline Magnoliaceae & Magnolia & soulangeana & 20.64 & & 254.18 & & 90.60 & M & M & Deciduous \\
\hline Rosaceae & Malus & flavum & 17.69 & & 329.21 & & 127.54 & M & M & Deciduous \\
\hline Celastraceae & Maytenus & boaria & 26.12 & & 128.62 & & 109.55 & M & M & Evergreen \\
\hline Myrtaceae & Melaleuca & linariifolia & 5.85 & 6.92 & 605.81 & 791.30 & 194.80 & $\mathrm{~L}$ & $\mathrm{~L}$ & Evergreen \\
\hline
\end{tabular}




\begin{tabular}{|c|c|c|c|c|c|c|c|c|c|c|}
\hline Myrtaceae & Melaleuca & quinquenervia & 25.08 & 24.66 & 380.15 & 290.03 & 207.90 & $\mathrm{~L}$ & $\mathrm{~L}$ & Evergreen \\
\hline Meliaceae & Melia & azedarach & 14.60 & & 248.34 & & 70.96 & VL & $\mathrm{L}$ & Deciduous \\
\hline Myrtaceae & Metrosideros & excelsa & 55.22 & & 106.58 & & 235.29 & $\mathrm{~L}$ & $\mathrm{~L}$ & Evergreen \\
\hline Moraceae & Morus & alba & 19.10 & & 600.31 & & 100.54 & $\mathrm{M}$ & M & Deciduous \\
\hline Scrophulariaceae & Myoporum & laetum & 29.01 & 30.38 & 115.07 & 115.07 & 71.84 & $\mathrm{~L}$ & $\mathrm{~L}$ & Evergreen \\
\hline Fabaceae & Parkinsonia & aculeata & 14.18 & 16.72 & 197.44 & 189.70 & 111.82 & VL & $\mathrm{L}$ & Deciduous \\
\hline Arecaceae & Phoenix & canariensis & 18.08 & 17.63 & 168.52 & 196.05 & 258.86 & $\mathrm{~L}$ & $\mathrm{~L}$ & Evergreen \\
\hline Anacardiaceae & Pistacia & chinensis & 17.01 & & 614.52 & & 116.23 & $\mathrm{~L}$ & $\mathrm{~L}$ & Deciduous \\
\hline Pittosporaceae & Pittosporum & undulatum & 21.66 & & 359.62 & & 95.47 & $\mathrm{~L}$ & $\mathrm{~L}$ & Evergreen \\
\hline Platanaceae & Platanus & $\times$ hispanica & 30.24 & & 186.46 & & 95.88 & M & M & Deciduous \\
\hline Podocarpaceae & Podocarpus & macrophyllus & 29.22 & & 174.73 & & 132.80 & M & M & Evergreen \\
\hline Salicaceae & Populus & nigra & 19.59 & & 233.53 & & 75.99 & M & $\mathrm{M}$ & Deciduous \\
\hline Rosaceae & Prunus & cerasifera & 14.20 & & 389.31 & & 70.83 & M & M & Deciduous \\
\hline Rosaceae & Prunus & serrulata & 12.84 & & 449.08 & & 115.70 & M & M & Deciduous \\
\hline Rosaceae & Pyrus & calleryana & 27.11 & & 173.49 & & 85.47 & $\mathrm{M}$ & $\mathrm{M}$ & Deciduous \\
\hline Rosaceae & Pyrus & kawakamii & 29.84 & & 172.18 & & 138.18 & M & M & Evergreen \\
\hline Fagaceae & Quercus & agrifolia & 12.78 & & 391.38 & & 139.33 & VL & $\mathrm{L}$ & Evergreen \\
\hline Anacardiaceae & Rhus & lancea & 19.49 & & 367.96 & & 127.59 & $\mathrm{~L}$ & $\mathrm{~L}$ & Evergreen \\
\hline Anacardiaceae & Schinus & molle & 20.93 & 21.73 & 117.93 & 108.13 & 137.58 & VL & $\mathrm{L}$ & Evergreen \\
\hline Proteaceae & Stenocarpus & sinuatus & 22.91 & & 235.41 & & 190.25 & M & M & Evergreen \\
\hline Arecaceae & Syagrus & romanzoffiana & 25.72 & 20.72 & 54.92 & 54.92 & 102.80 & $\mathrm{~L}$ & $\mathrm{~L}$ & Evergreen \\
\hline Euphorbiacae & Triadica & sebifera & 19.71 & & 181.60 & & 70.48 & M & M & Deciduous \\
\hline Ulmaceae & Ulmus & parvifolia & 27.52 & & 408.39 & & 115.41 & $\mathrm{~L}$ & $\mathrm{~L}$ & Evergreen \\
\hline Arecaceae & Washingtonia & robusta & 12.78 & 12.67 & 301.14 & 311.46 & 163.40 & $\mathrm{~L}$ & $\mathrm{~L}$ & Evergreen \\
\hline Ulmaceae & Zelkova & serrata & 23.37 & & 262.12 & & 82.96 & M & M & Deciduous \\
\hline
\end{tabular}




\section{APPENDIX B. LEAF FUNCTIONAL TRAITS BY FAMILY}

Distribution of leaf functional trait values (mean abaxial stomatal length, mean abaxial stomatal density, and mean LMA) for all families arranged from lowest to highest value may provide insight on how functional traits relate to phylogenetic relationships.

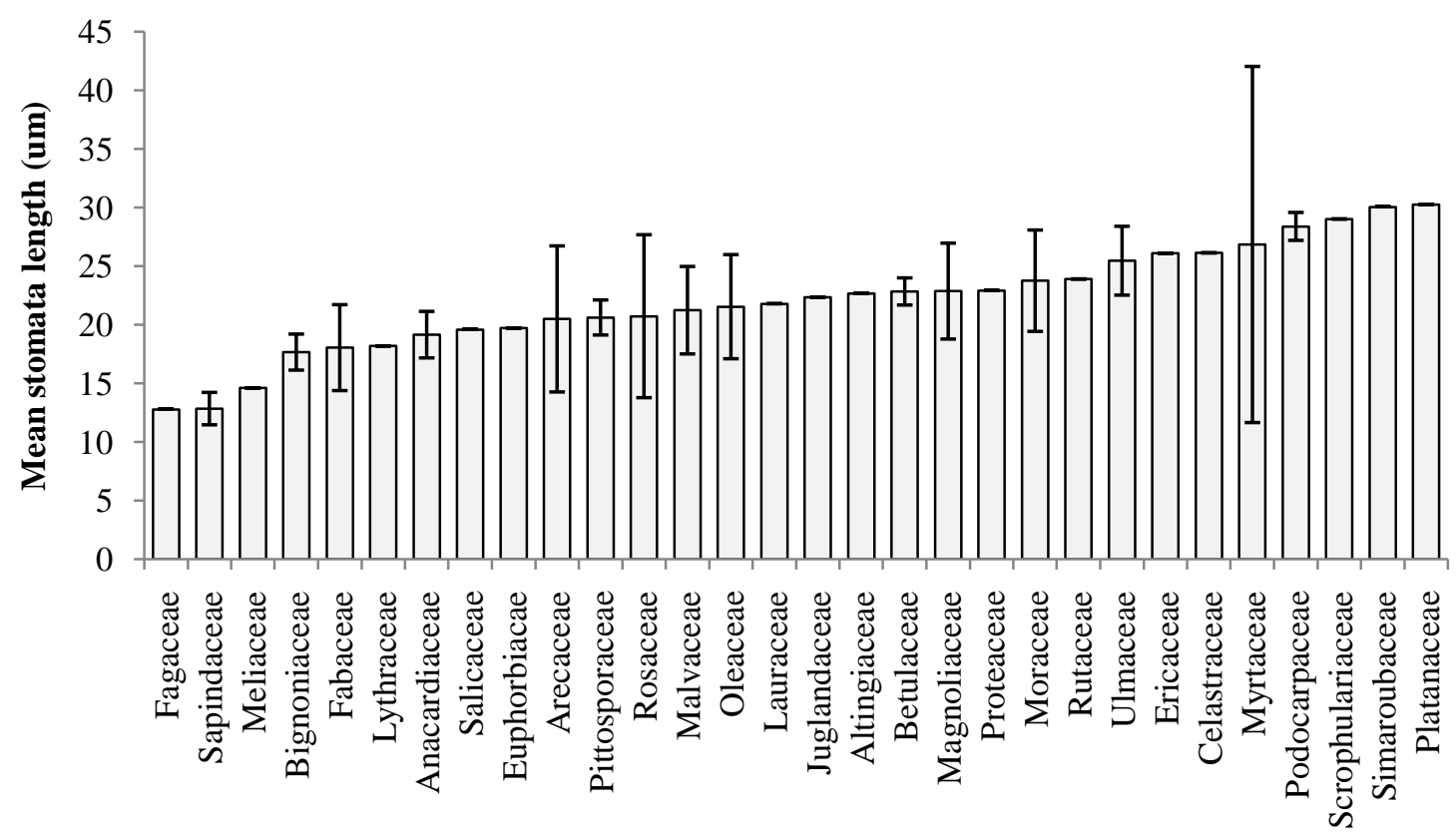

Family

Figure 13. Mean Stomata Length $(\boldsymbol{\mu m})$ of 30 Families. Only abaxial stomatal lengths are measured and shown. Error bars show standard deviation for families with more than one genus sampled. 


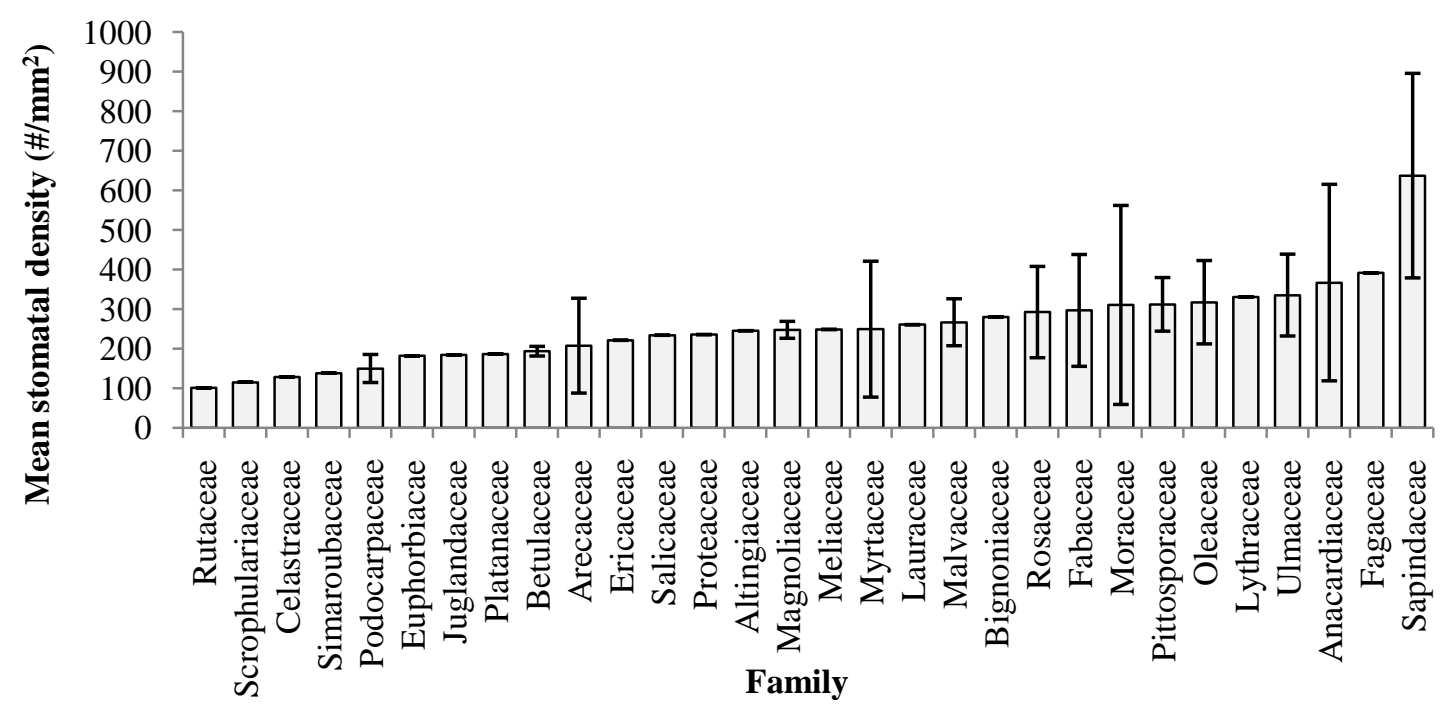

Figure 14. Mean Stomatal Density $\left(\# / \mathrm{mm}^{2}\right)$ of 30 Families. Only abaxial stomatal densities are measured and shown. Error bars show standard deviation for families with more than one genus sampled.

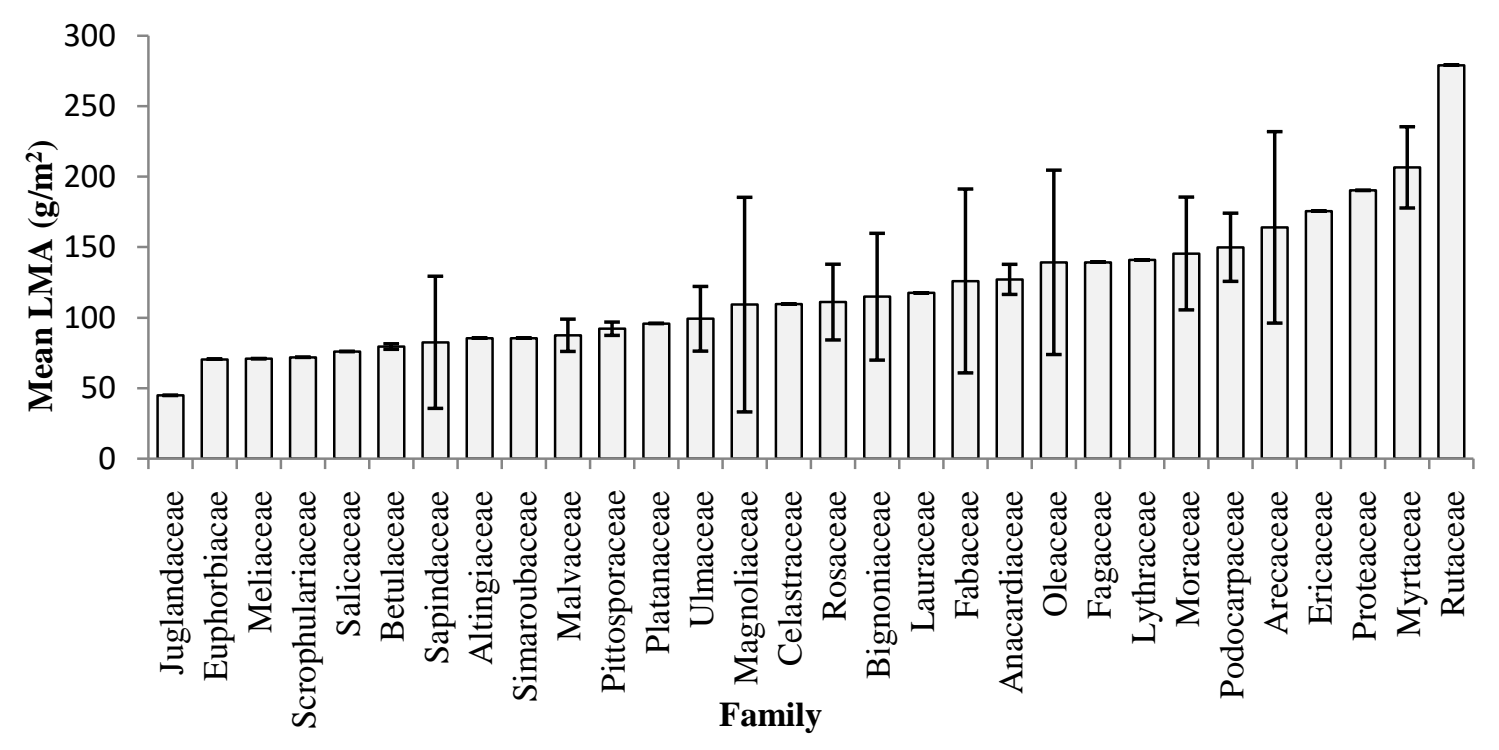

Figure 15. Average Leaf Mass per Area (LMA) g/m² ${ }^{2}$ of 30 Families. Error bars show standard deviation for families with more than one genus sampled. 


\section{APPENDIX C. URBAN TREE WATER USAGE FROM VARIOUS SOURCES}

Recommendations for water usage of urban landscape trees are highly variable. Information from a few common California landscape and gardening sources shows different irrigation and sun exposure categories in addition to descriptive advice. The Water Use Classification of Landscape Plants (Costello and Jones, 2014) assigns species water use relative to the regional ET 0 as does Perry in his usage of plant factors (PF) (Perry, 2010) (Table 3). Perry also incorporates the concept of irrigation groups (IG), where a value of two designates reduced summer irrigation and a value of one designates more even irrigation year round (Perry, 2010). The New Sunset Western Gardening Book (Brenzel, 2012) provides a combination of recommended solar environments and watering schedules (Table 3). Sterman in A California Gardener's Guide, Volume II does not use defined categories, but rather describes recommended plant care and watering routines (Sterman, 2007). A clear, consistent method for assessing water usage in landscape trees is lacking. 
Table 3. Water Usage of Eight Representative Urban Tree Species Common in California. Sources: WUCOLS, Landscape Plants for California Gardens by Bob Perry ( $\mathrm{IG}=$ irrigation group, $\mathrm{PF}=$ plant factor), New Sunset Western Gardening $\underline{B}$ ook, and California Gardener's Guide, Volume II by Nancy Sterman. Any climate zone specific recommendations were collected from zones including the city of San Luis Obispo for consistent comparison.

\begin{tabular}{|c|c|c|c|c|c|c|}
\hline \multirow{3}{*}{ Species } & \multicolumn{6}{|c|}{ Water Use/Care Suggestions } \\
\hline & \multirow{2}{*}{ WUCOLS } & \multicolumn{2}{|c|}{ Perry } & \multicolumn{2}{|c|}{ Sunset } & \multirow{2}{*}{ Sterman } \\
\hline & & IG & PF & Sun & Water & \\
\hline Acer palmatum & $\mathrm{M}$ & 1 & $\mathrm{H}$ & full/part shade & $\begin{array}{l}\text { moderate to } \\
\text { regular }\end{array}$ & Water regularly, slowly, deeply. \\
\hline Aesculus californica & $\mathrm{L}$ & 2 & $\mathrm{~L} / \mathrm{VL}$ & full & $\begin{array}{l}\text { regular, except } \\
\text { as noted }\end{array}$ & $\begin{array}{l}\text { Moist soil around young trees; water } \\
\text { occasionally the first summer. }\end{array}$ \\
\hline Arbutus 'Marina' & $\mathrm{L}$ & 2 & $\mathrm{~L} / \mathrm{M}$ & full & little to regular & $\begin{array}{l}\text { Keep roots moist, not wet in first year. } \\
\text { Occasional deep summer water after } \\
\text { established. }\end{array}$ \\
\hline $\begin{array}{l}\text { Archontophoenix } \\
\text { cunninghamiana }\end{array}$ & M & 1 & M & full/part shade & $\begin{array}{l}\text { moderate to } \\
\text { regular }\end{array}$ & Water regularly to keep soil moist, not wet. \\
\hline $\begin{array}{l}\text { Jacaranda } \\
\text { mimosifolia }\end{array}$ & M & 1 & M & full & moderate & $\begin{array}{l}\text { Frequent watering when young, but not wet. } \\
\text { Occasional watering when mature but err on } \\
\text { dry side. }\end{array}$ \\
\hline Metrosideros excelsa & $\mathrm{L}$ & 2 & $\mathrm{~L} / \mathrm{M}$ & $\begin{array}{l}\text { best in sun, some } \\
\text { shade }\end{array}$ & moderate & $\begin{array}{l}\text { Water young trees regularly spring to early } \\
\text { fall. Little to no water when mature. }\end{array}$ \\
\hline Pistacia chinensis & $\mathrm{L}$ & 1 & M & full & no to regular & $\begin{array}{l}\text { Water infrequently when established } \\
\text { especially in soils that don't drain well. }\end{array}$ \\
\hline Quercus agrifolia & $\mathrm{L}$ & 2 & $\mathrm{~L} / \mathrm{M}$ & full & variable & $\begin{array}{l}\text { Deep irrigation until established. Little to no } \\
\text { water when mature. }\end{array}$ \\
\hline
\end{tabular}

